\title{
Primary $U$ distribution in scleractinian corals and its implications for $U$ series dating
}

\author{
Laura F. Robinson \\ California Institute of Technology, MS 100-23, 1200 East California Boulevard, Pasadena, California 91125, USA
}

Now at Department of Marine Chemistry and Geochemistry, Woods Hole Oceanographic Institute, Woods Hole, Massachusetts 02543, USA. (Irobinson@whoi.edu)

Jess F. Adkins, Diego P. Fernandez, Donald S. Burnett, S.-L. Wang, Alexander C. Gagnon, and Nir Krakauer

California Institute of Technology, MS 100-23, 1200 East California Boulevard, Pasadena, California 91125, USA

[1] In this study we use microsampling techniques to explore diagenetic processes in carbonates. These processes are important as they can affect the accuracy of $U$ series chronometry. Fission track maps of deep-sea scleractinian corals show a threefold difference between the minimum and maximum [U] in modern corals, which is reduced to a factor of 2 in fossil corals. We use micromilling and MC-ICP-MS to make detailed analyses of the $[\mathrm{U}]$ and $\delta^{234} \mathrm{U}_{\text {initial }}$ distributions in corals from 218 ka to modern. Within each fossil coral we observe a large range of $\delta^{234} U_{\text {initial }}$ values, with high $\delta^{234} U_{\text {initial }}$ values typically associated with low $[\mathrm{U}]$. A simple model shows that this observation is best explained by preferential movement of alpha-decay produced ${ }^{234} \mathrm{U}$ atoms (alpha-recoil diffusion). Open-system addition of ${ }^{234} \mathrm{U}$ may occur when alpha-recoil diffusion is coupled with a high [U] surface layer, such as organic material. This process can result in large, whole-coral $\delta^{234} U_{\text {initial }}$ elevations with little effect on the final age. The diagenetic pathways that we model are relevant to both shallow-water and deep-sea scleractinian corals since both exhibit primary $[\mathrm{U}]$ heterogeneity and may be subject to $\mathrm{U}$ addition.

Components: 10,258 words, 12 figures, 2 tables.

Keywords: uranium; diagenesis; coral; dating.

Index Terms: 1040 Geochemistry: Radiogenic isotope geochemistry; 1120 Geochronology: Isotopic disequilibrium dating; 4916 Paleoceanography: Corals (4220).

Received 6 September 2005; Revised 3 December 2005; Accepted 10 March 2006; Published 24 May 2006.

Robinson, L. F., J. F. Adkins, D. P. Fernandez, D. S. Burnett, S.-L. Wang, A. C. Gagnon, and N. Krakauer (2006), Primary U distribution in scleractinian corals and its implications for U series dating, Geochem. Geophys. Geosyst., 7, Q05022, doi:10.1029/2005GC001138.

\section{Introduction}

[2] U series isotopes in biogenic carbonates provide vital information in our understanding of past climate. The most important application is the use of $\mathrm{U}$ decay to $\mathrm{Th}$ and $\mathrm{Pa}$ providing two precise chronometers suited to dating climate events over the last few hundred thousand years [Broecker,
1963; Edwards et al., 1986, 1997; Stirling et al., 1995]. In addition to dating, the uranium concentration ([U]) in carbonates has been used to constrain past water mass properties [Min et al., 1995; Shen and Dunbar, 1995; Russell et al., 2004] and uranium isotope variability has also been linked to past climate and weathering patterns [Robinson et $a l ., 2004 a]$. To make full use of $U$ series isotopes in ancient carbonates, we must understand the two 
key controls on the final, measured $U$ series distribution: the initial incorporation and any subsequent diagenesis.

[3] Uranium is found as a trace metal in both calcite and aragonite [Djogic et al., 1988; Pingitore et al., 2002]. The octahedral shape of the tetravalent uranyl carbonate ion is, however, more readily included in the aragonite lattice than the calcite lattice [Reeder et al., 2001]. The resulting high [U] in aragonite causes the skeletons of scleractinian corals to be ideally suited to precise $U$ series measurements. Shallow-water corals have a heterogeneous $U$ distribution that typically follows the growth banding, and displays a negative correlation to growth temperature [Min et al., 1995]. This relationship can be complicated by a number of other parameters such as $\mathrm{pH}$ at the calcification site, carbonate ion concentration, or growth rate [Shen and Dunbar, 1995]. Modern shallow-water corals display two additional types of uranium heterogeneity that have not been linked to environmental controls: enrichment by up to a factor of two at septal edges and "random" small scale variations [Schroeder et al., 1970].

[4] An obvious test of whether diagenesis affects the primary $U$ distribution is to compare modern and fossil samples of similar material. Modern corals have typical [U] of 2.0-3.5 ppm [Shen and Dunbar, 1995]. Within 1 kyr (thousand years) of death, the coral pores can become partially filled with aragonite that is enriched in uranium relative to the original coral skeleton [Lazar et al., 2004]. Swart and Hubbard [1982] showed that fossil corals had [U] up to $6 \mathrm{ppm}$ in areas that had been affected by endolithic borings. They also showed that dead, nonbioeroded corals soaked in concentrated $\mathrm{U}$ solutions developed $\mathrm{U}$ enrichment along skeletal margins and trabecular centers, demonstrating a rapid diagenetic pathway for $U$ addition.

[5] A second measure of diagenetic activity is the $\mathrm{U}$ isotope activity ratio $\left({ }^{234} \mathrm{U} /{ }^{238} \mathrm{U}\right)$. Marine carbonates incorporate the isotopic ratio (denoted as $\delta^{234} \mathrm{U}\left(=\left(\left[\left(^{234} \mathrm{U} /{ }^{238} \mathrm{U}\right)\right.\right.\right.$ meas $\left.\left./\left({ }^{234} \mathrm{U} /{ }^{238} \mathrm{U}_{\mathrm{eq}}\right)\right]-1\right)$ $\times 10^{3}$ ) of the seawater in which they grow [e.g., Broecker and Takahashi, 1966; Robinson et al., 2004b]. This value is invariant throughout the water column [Cheng et al., 2000a] and has been constant $(\sim 146 \%)$ ) to within $\sim 10 \%$ over the last several hundred thousand years [Bard et al., 1991; Stirling et al., 1995; Henderson, 2002]. For a closed-system, the $\delta^{234} U_{\text {initial }}\left(\delta^{234} U_{\text {initial }}=\right.$ $\delta^{234} \mathrm{Ue}^{\lambda t}$ ) should be identical to that of the modern day [Edwards et al., 1986]. However, the $\delta^{234} U_{\text {initial }}$ values of fossil carbonates exhibit increasing scatter, and tend to be more elevated at greater ages (Figure 1) [e.g., Bender et al., 1979; Henderson, 2002]. These differences have been attributed to diagenesis, and so the associated U-Th ages are potentially inaccurate [Gallup et al., 1994]. However, this indicator does not necessarily guarantee a reliable age, since paired U-Th and U-Pa ages can return different ages even with $\delta^{234} U_{\text {initial }}$ values that reflect seawater. Conversely, some concordant U-Th, U-Pa ages have $\delta^{234} U_{\text {initial }}$ values that are elevated or depleted [Cutler et al., 2003]. This observation means that we must look carefully at the processes of $U$ series redistribution, gain and loss if we are to determine accurate ages.

[6] A number of models have been developed to try and back-calculate meaningful ages from diagenetically altered carbonates [Bender et al., 1979; Gallup et al., 1994; Henderson et al., 2001; Thompson et al., 2003; Villemant and Feuillet, 2003; Scholz et al., 2004]. Bender et al. [1979] and Gallup et al. [1994] explained the isotopic trends observed in Barbados corals through addition of ${ }^{234} \mathrm{U}$ and ${ }^{230} \mathrm{Th}$. Scholz et al. [2004] modeled a suite of corals that were exposed to meteoric waters by applying episodic pulses of $\mathrm{U}$ loss and gain, with the $\delta^{234} \mathrm{U}$ of the additional uranium determined by making multiple measurements on subsamples from the same coral. This empirical model reveals the diagenetic history of a single coral, but is not able to explain the $\delta^{234} U_{\text {initial }}$ distribution of corals from a wide range of environments.

[7] Henderson et al. [2001] observed variable $\delta^{234} \mathrm{U}$ in mineral separates from carbonate sediments and developed a model allowing preferential movement of isotopes produced by alpha recoil $\left({ }^{234} \mathrm{Th}\right.$ and $\left.{ }^{230} \mathrm{Th}\right)$ between sedimentary grains with different [U]. Both Thompson et al. [2003] and Villemant and Feuillet [2003] developed models based on this process of alpha-recoil mobilization. Villemant and Feuillet [2003] proposed a model with continuous gain or loss of ${ }^{234} \mathrm{U},{ }^{234} \mathrm{Th}$ and ${ }^{230} \mathrm{Th}$ and allowed for the possibility of initial ${ }^{230} \mathrm{Th}$ in the coral skeleton. Thompson et al. [2003] modeled the transport of decay produced ${ }^{230} \mathrm{Th}$ or ${ }^{234} \mathrm{Th}$ from one sample to another. Th produced by decay in one coral may be adsorbed directly onto another coral, alternatively this Th, or Th produced in the pore water itself, may be transported by the pore waters and then adsorbed onto a secondary coral sample. Thompson et al. 


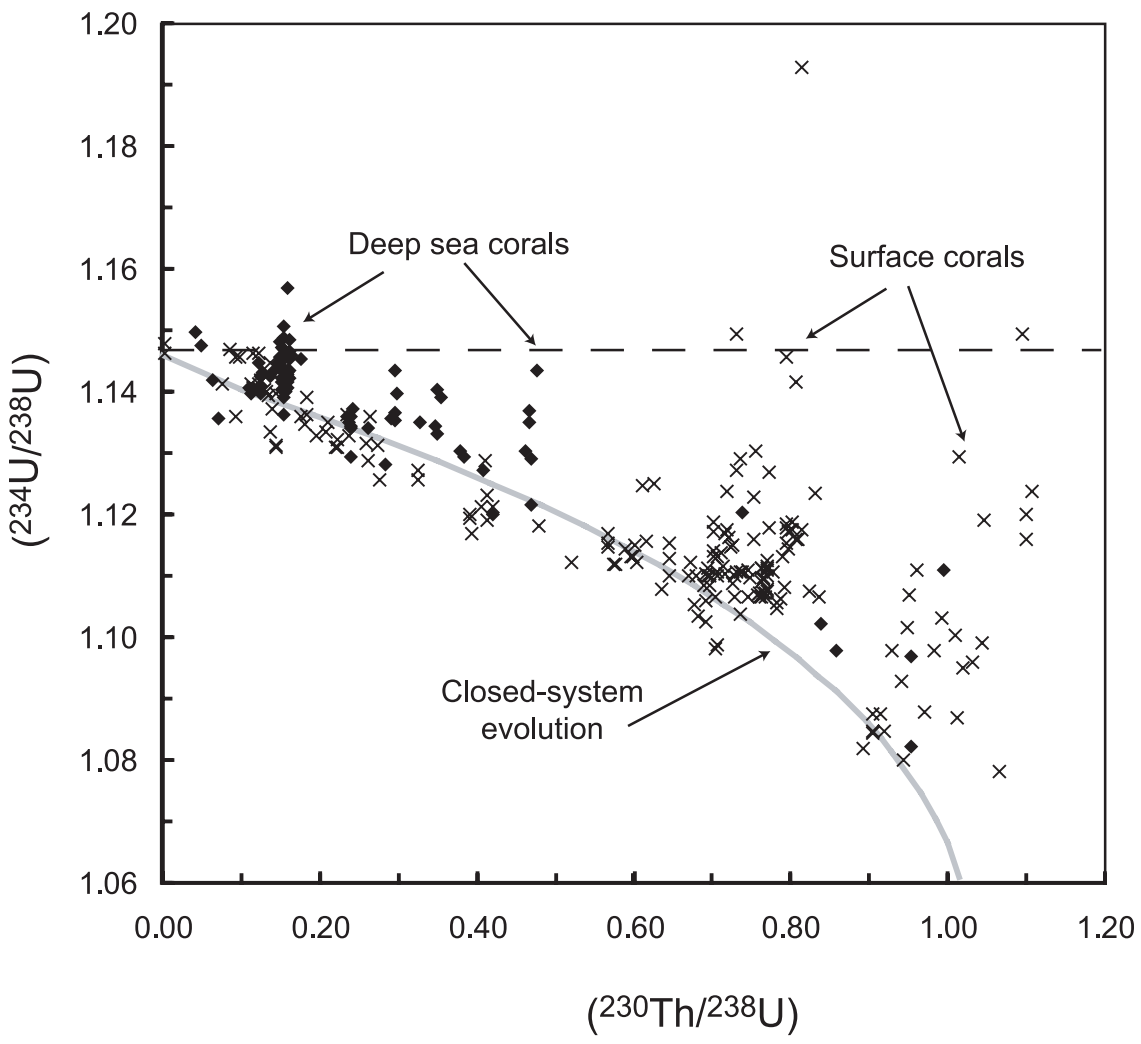

Figure 1. Comparison of measured deep-sea (diamonds) and shallow-water coral (crosses) $\left({ }^{234} \mathrm{U} /{ }^{238} \mathrm{U}\right)$ and $\left({ }^{230} \mathrm{Th} /{ }^{238} \mathrm{U}\right)$ values. Deep-sea coral data are from this study (Table 1) and Robinson et al. [2005]. Shallow-water coral data are from Bard et al. [1990a, 1990b], Szabo et al. [1994], Cutler et al. [2003], and Thompson et al. [2003]. The solid gray line shows the isotopic evolution of a closed system starting with a $\left({ }^{234} \mathrm{U} /{ }^{238} \mathrm{U}\right)$ of 1.1465 and a $\left({ }^{230} \mathrm{Th} /{ }^{238} \mathrm{U}\right)$ of zero. Deviations from this line are symptomatic of diagenetic alteration from a closed system. The dashed line is at the modern seawater $\left({ }^{234} \mathrm{U} /{ }^{238} \mathrm{U}\right)$ activity ratio, and any points that fall above it cannot be explained by diagenetic replacement of $U$ with the seawater $\left({ }^{234} \mathrm{U} /{ }^{238} \mathrm{U}\right)$ ratio only.

[2003] used their model to generate broadly consistent open-system ages for data from corals from uplifted terraces in a number of locations. Despite the improved agreement between coral individuals, the ages still exhibit scatter, indicating that more than one process is causing $U$ and Th diagenesis.

[8] Deep-sea scleractinian corals may provide us with a key to understanding both primary $U$ incorporation, and the mechanisms controlling its redistribution with time. Fossil shallow-water and deep-sea corals have overlapping $\delta^{234} U-$ $\left({ }^{230} \mathrm{Th} /{ }^{238} \mathrm{U}\right)$ distributions, suggesting that they are affected by similar diagenetic processes (Figure 1). In this study we use solitary, ahermatypic, scleractinian corals of the species Desmophyllum dianthus (formerly known as $D$. cristagalli) to investigate $\mathrm{U}$ series diagenesis. Each coral has an expected life time of $\sim 100$ years [Adkins et al., 2004] during which time the deep ocean is unlikely to undergo multiple climate shifts. Therefore, especially in the horizontal plane perpendicular to the growth axis, we do not expect the coral to record frequent, large oscillations in ambient growth temperature or chemical composition, such as those recorded in shallow-water corals. Certain deep-sea corals may, however, live through abrupt variability [Adkins et al., 1998; Robinson et al., 2005] but even these changes will not affect the [U] or $\delta^{234} \mathrm{U}$ of the seawater surrounding the coral. Primary [U] variability such as that observed by Montagna et al. [2005] is therefore expected to be controlled by physiological processes, typically referred to as vital effects. Throughout their diagenetic history the corals are bathed in seawater with unchanging [U] and $\delta^{234} \mathrm{U}$, so open-system behavior must be the result of bioerosion or interaction with seawater.

[9] In addition to informing us about diagenetic processes in shallow-water scleractinian corals, understanding the chemistry of deep-sea corals is important because of their intrinsic value as directly datable high-resolution archives of deep-ocean 


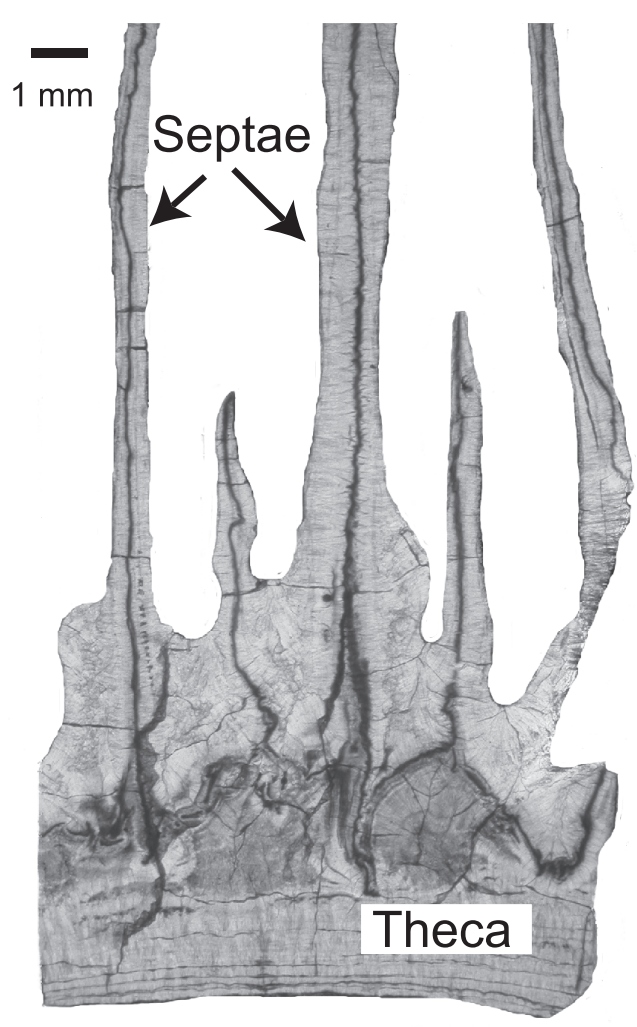

(a) Theca with septae orthogonal to growth axis

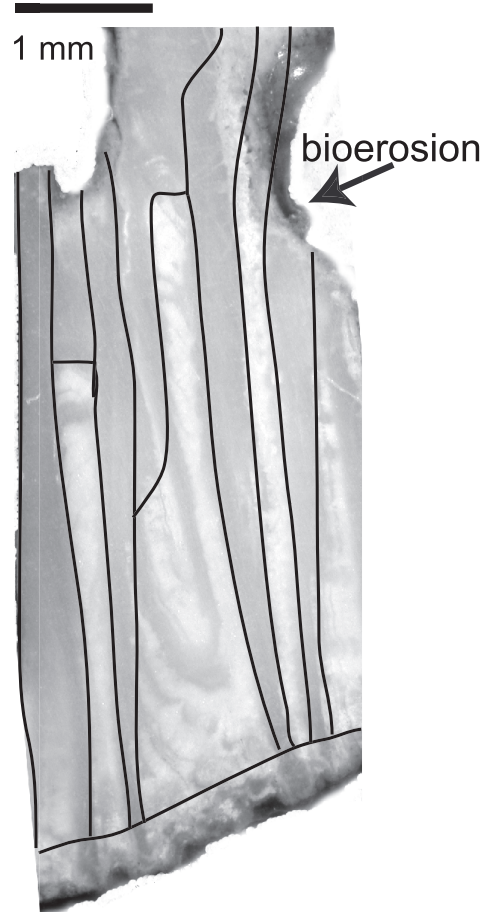

(b) $11 \mathrm{ka}$ theca

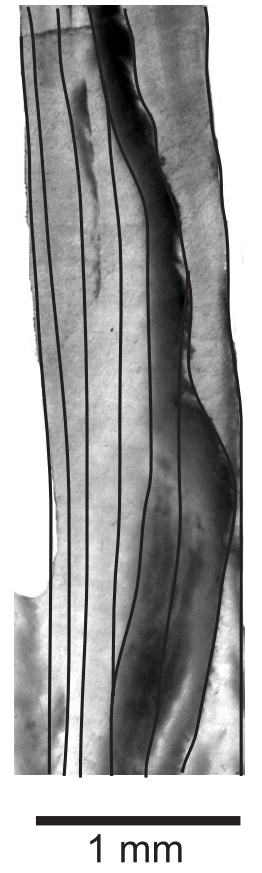

(c) 44 ka septum

Figure 2. Figure 2 shows reflected light images of three D. dianthus sections oriented orthogonally to the growth axis. Figure $2 \mathrm{a}$ labels the thecal and septal areas of a modern coral. Figure $2 \mathrm{~b}$ is a thecal section from an $11 \mathrm{ka}$ coral. The irregular surfaces (which have a brown discoloration) at the bottom and at the upper right-hand side of the figure are caused by endolithic boring. Figure $2 \mathrm{c}$ is a section through the septum of a $44 \mathrm{ka}$ coral. The black lines in Figures $2 \mathrm{~b}$ and $2 \mathrm{c}$ delimit micromill subsampling, which aimed to follow the visible banding. The limitations to the precision of micromilling mean that some slices sampled both dark and light colored bands.

variability [Smith et al., 1997, 2000; Adkins et al., 1998; Lomitschka and Mangini, 1999; Cheng et al., 2000a; Goldstein et al., 2001; Schroder-Ritzrau et al., 2003; Frank et al., 2004; Robinson et al., 2005]. In this study we use two approaches to test the assumptions made in dating biogenic carbonates; we compare whole-coral U-Th isotope measurements from shallow-water and deep-sea corals and we map out the $[\mathrm{U}]$ and $\delta^{234} \mathrm{U}$ distribution from the $10 \mathrm{~s} \mu \mathrm{m}$ to $\mathrm{cm}$ scale in modern and fossil deep-sea corals over a $218 \mathrm{kyr}$ time period.

\section{Methods}

[10] Multiple polished thin sections from two corals (modern and $33 \mathrm{ka}$ ) were mounted flush against micas and subjected to neutron bombardment to induce fission of ${ }^{235} \mathrm{U}$ [Murrell and Burnett, 1982]. The coral sections experienced fluences of either $1 \times 10^{16} \mathrm{~cm}^{-2}$ or $5 \times 10^{16} \mathrm{~cm}^{-2}$. The resulting fission tracks recorded on the mica were etched in concentrated HF for 25-30 minutes, and imaged by scanning electron microscopy (SEM). The relative $[\mathrm{U}]$ is determined by dividing the coral into equal-area boxes and counting the number of fission tracks using NIH-ImageJ software. The size of these boxes, $25 \times 200 \mu \mathrm{m}$ was chosen to give a minimum of 100 counts in low [U] areas with associated counting statistics of $10 \%$ and an associated sample resolution of $\sim 25 \mu \mathrm{m}$ perpendicular to the banding. The isotropic production of fission products from a single ${ }^{235} \mathrm{U}$ atom can limit our spatial resolution by producing tracks on the mica in a wider area than the position of a point source. On the basis of an estimate of the path length of the fission products in aragonite we estimate our minimum spatial resolution to be about $10 \mu \mathrm{m}$.

[11] Samples of $\sim 1 \mathrm{~g}$ were taken from each of 42 corals which were then physically and chemically cleaned to remove the coating ferromanganese 

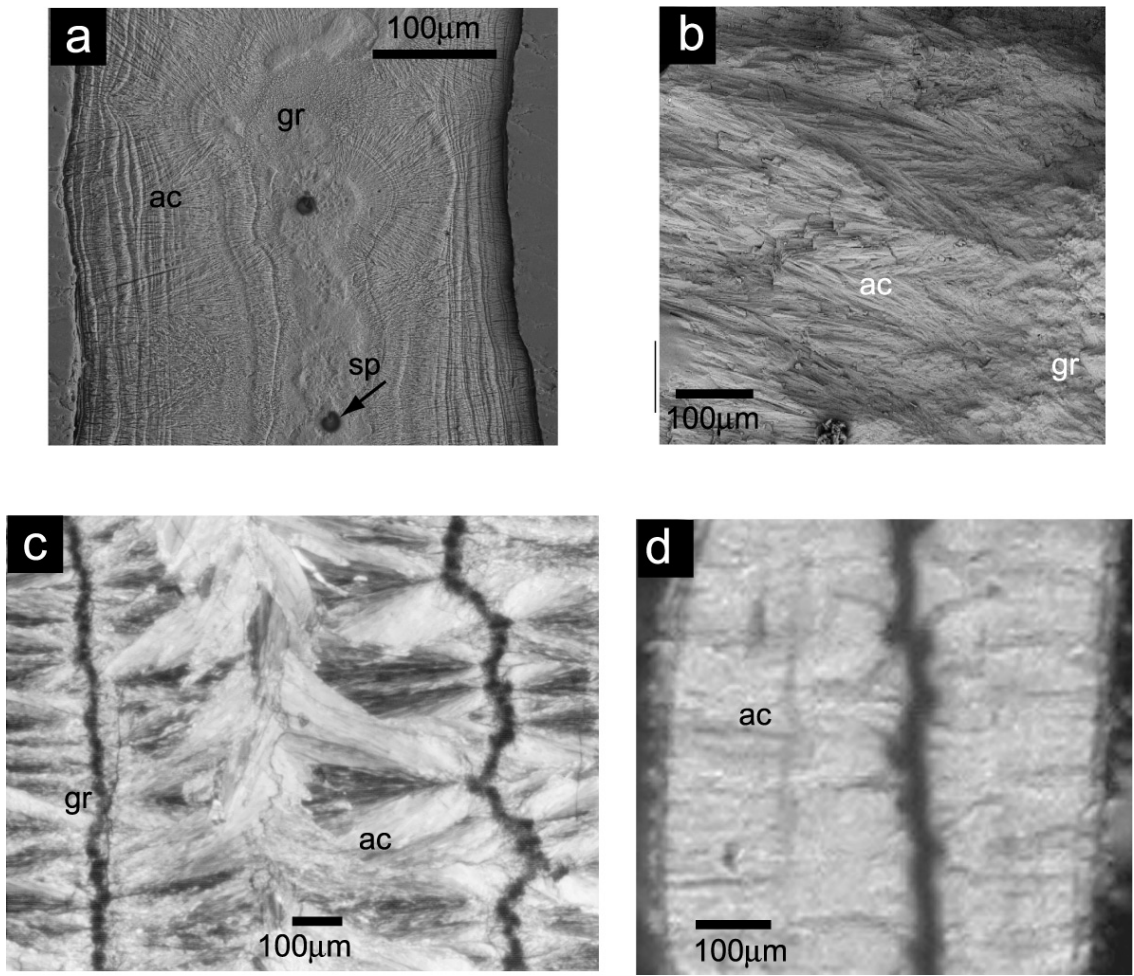

Figure 3. The four images show the banding present in the horizontal plane of D. dianthus, together with approximate scale bars. Figure 3a is an SEM image of an etched thin section across a coral septum. The central band (aligned vertically) is filled by irregular fine-grained aragonite (gr), which is surrounded by elongated acicular crystals (ac). In the central band there are two dark colored features which have the appearance of collapsed spheres (labeled $\mathrm{sp}$ ). The longitudinal ridges across the acicular crystals are thought to be caused by preferential dissolution, perhaps due to variable organic or $\mathrm{Mg}$ content. Figure $3 \mathrm{~b}$ depicts an untreated fractured surface and highlights the difference between these two crystal morphologies. Figure $3 \mathrm{c}$ is a petrographic image from a thecal section. The two dark lines are equivalent to the single central band in the septal images, and their optical density may be due to the presence of multiple organic "spheres" integrated through the thickness of the section. The acicular crystals are clearly arranged in bunches aligned along their c axis. Figure $3 \mathrm{~d}$ is a transmitted light image of a coral septum and clearly displays the light and dark banding.

crust [Cheng et al., 2000a] and spiked with a mixed ${ }^{229} \mathrm{Th}-{ }^{236} \mathrm{U}$. U and Th were separated and purified by anion-exchange chemistry [Edwards et al., 1986]. The spike was calibrated to a 2 s.d. uncertainty of $0.4 \%$ using $\mathrm{HU}-1$, a U series standard close to secular equilibrium [Cheng et al., 2000b]. Purified aliquots of $U$ and Th were measured by Neptune multicollector inductively coupled mass spectrometer (MC-ICP-MS) with bracketing standards of CRM-145 for U, and an in-house Th standard calibrated against CRM-145 [Robinson et al., 2002, 2005]. Procedural blanks had an average value of $67 \mathrm{pg}$ for ${ }^{238} \mathrm{U}$ (less than $0.002 \%$ of the typical sample size) and $2 \mathrm{fg}$ for ${ }^{230} \mathrm{Th}$. The ${ }^{232} \mathrm{Th}$ concentration in each sample was monitored to assess the extent of contamination from the Th-rich ferromanganese crust not removed during cleaning. This ${ }^{232} \mathrm{Th}$ was then used to correct for initial ${ }^{230} \mathrm{Th}$ using a ${ }^{232} \mathrm{Th} /{ }^{230} \mathrm{Th}$ ratio of 12,500 $\pm 12,500$ [Cheng et al., 2000a].

[12] Thick sections of one modern and six fossil corals of known age (10.9 ka, $14.8 \mathrm{ka}, 16.2 \mathrm{ka}$, $43.9 \mathrm{ka}, 83.0 \mathrm{ka}$ and $218.5 \mathrm{ka}$ ) were polished and sampled by micromilling to give sample masses of $\sim 1 \mathrm{mg}$ of $\mathrm{CaCO}_{3}$. Typical spatial resolutions were 100-400 $\mathrm{m}$ perpendicular to the banding, with a drilling depth of $\sim 400 \mu \mathrm{m}$ (Figure 2). The difficulties of precise drilling mean that some samples intersect more than one type of mineral texture (Figure 2). Each sample was weighed, spiked using a pure ${ }^{236} \mathrm{U}$ spike, dissolved and taken through anion-exchange chemistry [Edwards et al., 1986]. The purified uranium was re-dissolved in 5\% nitric acid and aspirated into the MC-ICP-MS [Robinson et al., 2005]. An average of three procedural blanks gave $11 \mathrm{pg}$ of ${ }^{238} \mathrm{U}$. There is insufficient ${ }^{230} \mathrm{Th}$ to allow age measurements from each individual 


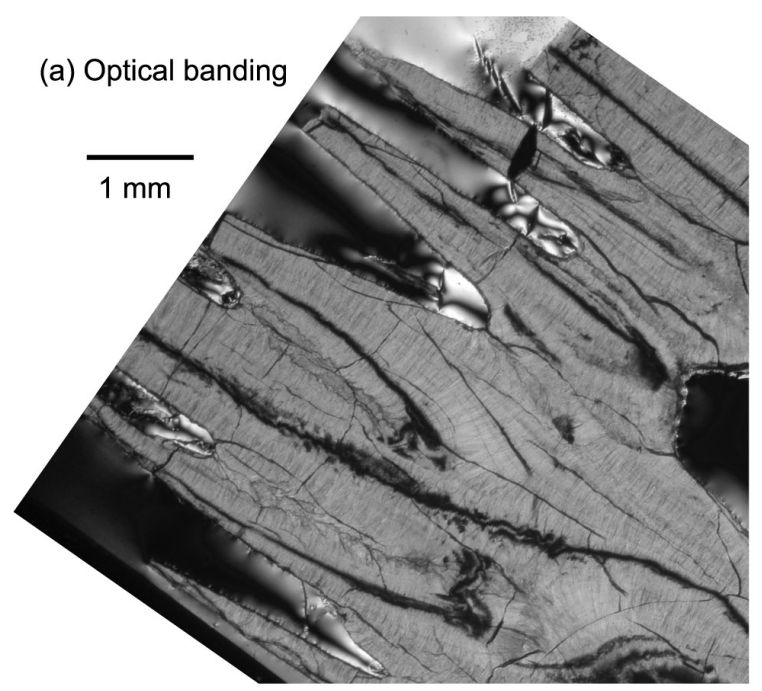

(b) Fission tracks

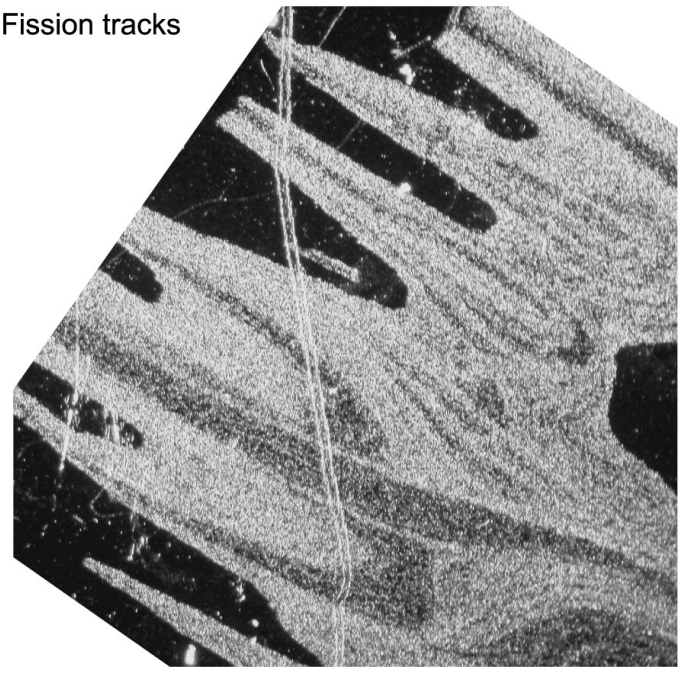

Figure 4. Two images of the same coral section compare the visible and fission track banding. Figure $4 \mathrm{a}$ shows the visible banding viewed though a transmitting light microscope. Figure $4 \mathrm{~b}$ is a reflected light image of the mica used to record the density of fission tracks generated by neutron bombardment. The dark areas have few fission tracks relative to the light areas. The fission track density is directly proportional to the $\left[{ }^{235} \mathrm{U}\right]$, which is, in turn, directly proportional to the $\left[{ }^{238} \mathrm{U}\right]$. These two images highlight the similarity between visible banding and [U], even in areas characterized by detailed variability.

subsample, so the age of the whole coral is used to calculate $\delta^{234} U_{\text {initial }}$.

\section{Results}

[13] D. dianthus has a complex banding pattern which is controlled by the calcification of the coral and is apparent both visually [Lazier et al., 1999] and in some aspects of its chemical composition [e.g., Adkins et al., 2003]. The aragonite in the central growth band of each septum comprises irregular fine-grained crystals which are surrounded by bunches of acicular crystals as seen in the etched and untreated SEM images in Figures $3 \mathrm{a}$ and $3 \mathrm{~b}$. In the central band of the etched SEM image there are two dark colored features whose amorphous shape suggests an organic origin (Figure 3a). These features are observed at the centre of the granular aragonite, and when stacked-up in a thin section contribute to the coloration of the dark banding seen in transmitted light images (Figures 2, 3c, and 3d).

[14] The [U] distribution in modern $D$. dianthus is heterogeneous, and has a spatial structure coherent with the visible banding. This coherency is best seen by comparing a fission track map and a transmitted light image of the same coral section (Figure 4). The central part of the coral septum is depleted in uranium, but the zone of depletion is wider than the transmitted light banding, over and above the $10 \mu \mathrm{m}$ spatial resolution of the fission tracks (Figure 5). The fission track density variations show that the difference between minimum and maximum $[\mathrm{U}]$ in modern corals is greater than a factor of 3 (Figures 5 and 6). Fission track maps from a $33 \mathrm{ka}$ fossil coral also show a quasi-bimodal

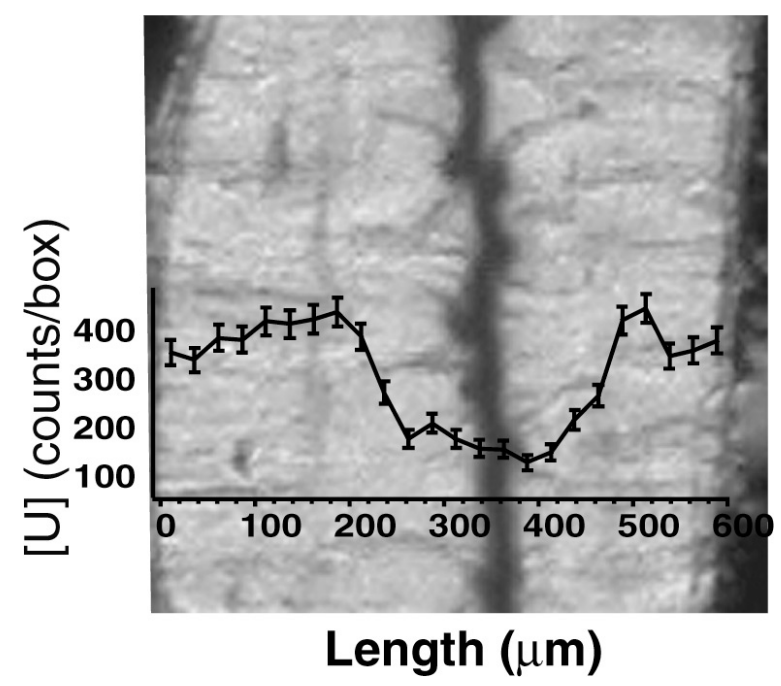

Figure 5. Figure 5 shows a fission track density profile overlying the transmitted light image of the visible banding and is an enlargement of Line 3 in Figure 6. The lowest [U] runs through the center of the septa but is wider than visible banding, indicating that the dark part of the visible banding does not control the $\mathrm{U}$ distribution. 


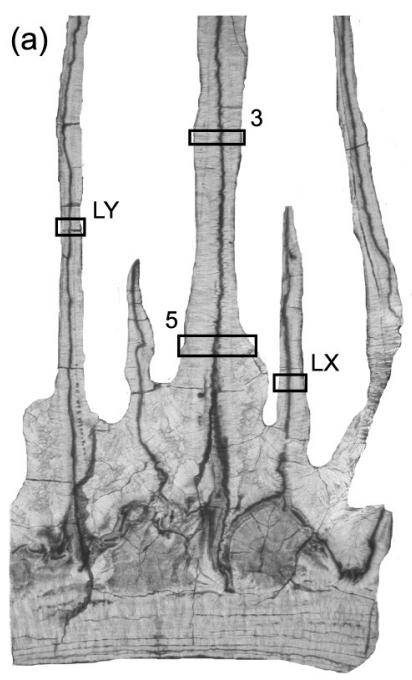

$\overline{1 \mathrm{~mm}}$
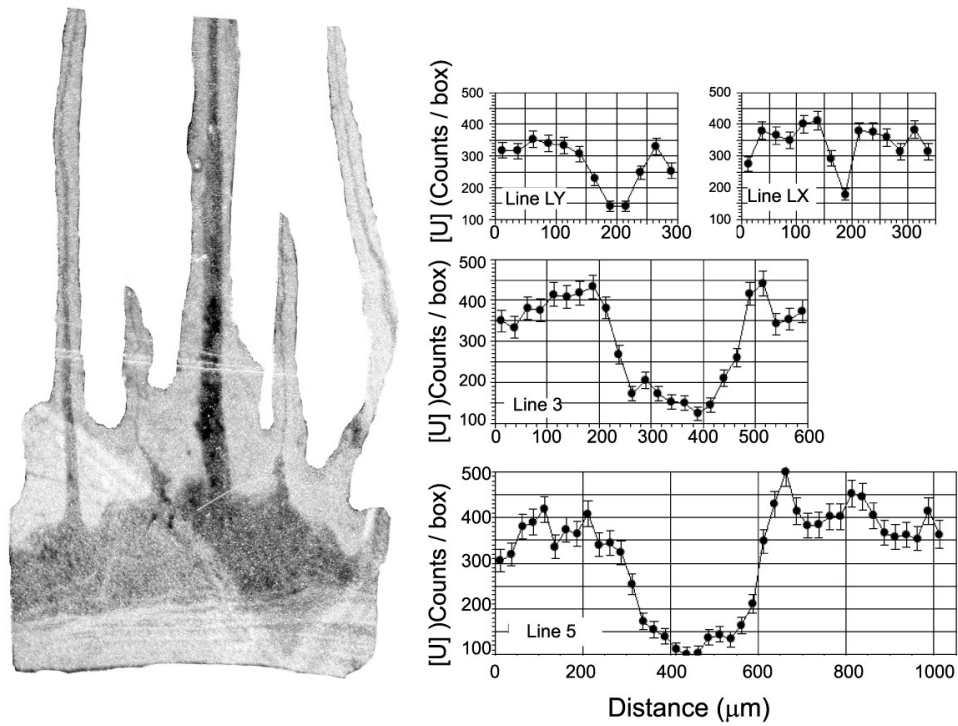
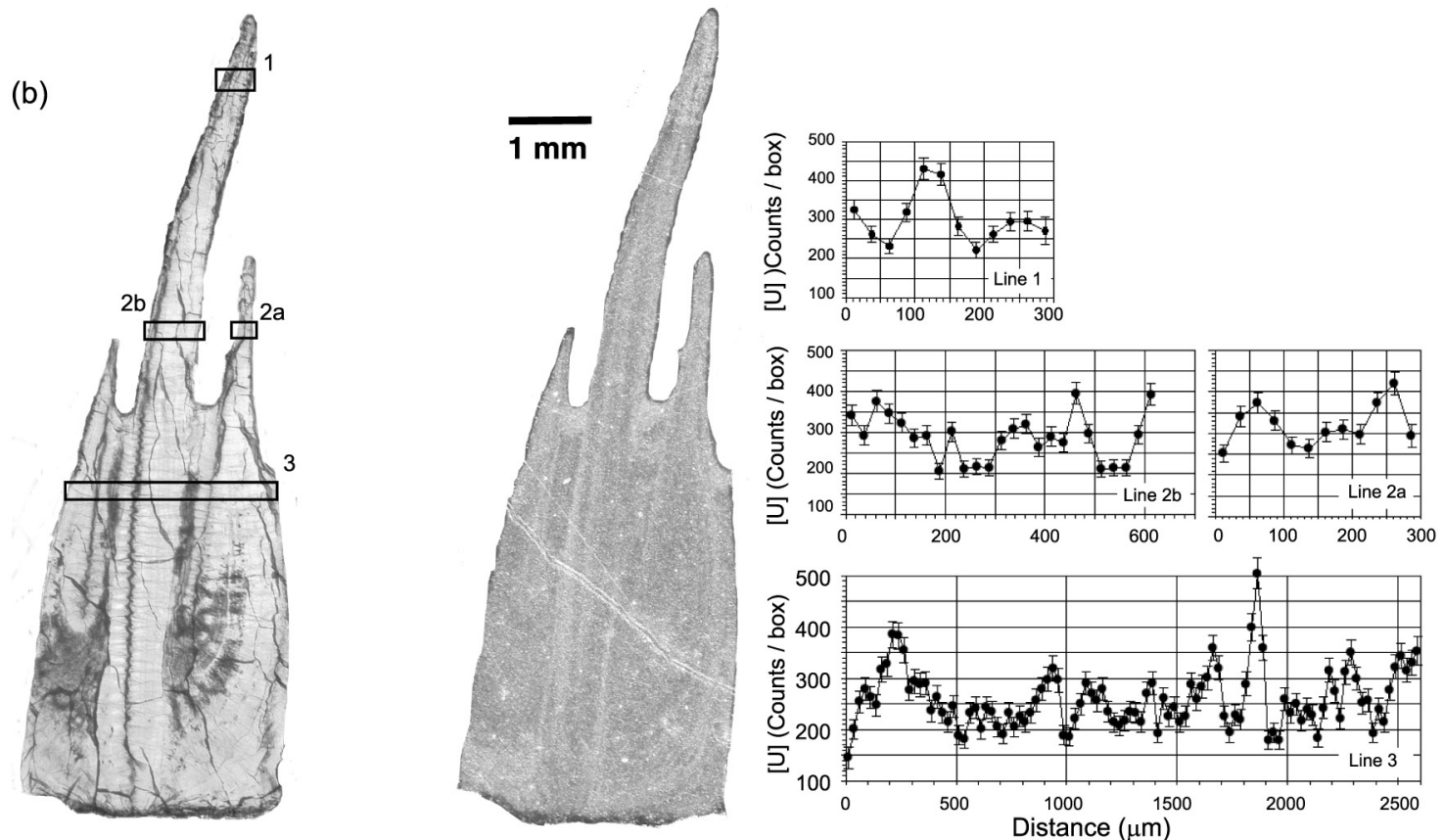

Figure 6. The two panels show visible banding (left), fission track density image (right), and four plots of relative [U] for (a) a modern coral and (b) a $33 \mathrm{ka}$ fossil coral. The fossil sample shows a significantly reduced contrast between high and low $[\mathrm{U}]$ bands ( $<$ factor of 2 ) compared to the modern coral (>factor of 3 ), but the detailed structure of the $\mathrm{U}$ heterogeneity is retained.

U distribution, but the contrast between U-depleted and U-enriched aragonite is significantly reduced, to at most a factor of 2 (Figure 6). Although difficult to pick out in the fossil image, quantification by track counting demonstrates that despite the $[\mathrm{U}]$ contrast reduction in the fossil coral, the boundaries are still sharp and retain their small length scale variability (Figure 6). The fission track maps shown in Figures 4, 5, and 6 are typical of the
$\mathrm{U}$ distribution, as measured multiple times in each coral, ruling out analytical artifacts such as a bad contact between the coral and mica as the cause of the contrast between modern and fossil corals.

[15] Micromilling integrates across a wider spatial scale $(100-400 \mu \mathrm{m})$ than the fission tracks and so may not capture the full $[\mathrm{U}]$ range. However, the $[\mathrm{U}]$ patterns are consistent with fission track data 
Table 1. Microsampled U Series Results From Seven Coral Sections, Ranging From Modern to $218 \mathrm{ka}^{\mathrm{a}}$

\begin{tabular}{|c|c|c|c|c|c|c|c|c|}
\hline & Width, $\mu \mathrm{m}$ & Weight, mg & \multicolumn{2}{|c|}{ [U], ppm } & $\delta^{234} U_{1}$ & $\%$ & \multicolumn{2}{|c|}{$\delta^{234} U_{\text {initial }}, \%$} \\
\hline \multicolumn{9}{|c|}{47407} \\
\hline \multirow{2}{*}{\multicolumn{9}{|c|}{$\begin{array}{l}\text { Age: Modern } \\
\delta^{234} U_{\text {initial }}=143.2 \pm 1.9 \% 0\end{array}$}} \\
\hline & & & & & & & & \\
\hline 47_Ba.1 & 2000 & 0.935 & 5.27 & 0.11 & 140.0 & 2.0 & 140.0 & 2.0 \\
\hline 47_Ва.2 & 875 & 1.085 & 5.02 & 0.09 & 141.0 & 2.1 & 141.0 & 2.1 \\
\hline 47_Ва.3 & 388 & 1.020 & 2.82 & 0.06 & 143.7 & 2.6 & 143.7 & 2.6 \\
\hline 47_-Ba.4 & 375 & 1.917 & 3.07 & 0.03 & 145.0 & 2.2 & 145.0 & 2.2 \\
\hline 47_Ва.5 & 88 & 0.799 & 3.63 & 0.09 & 143.7 & 2.6 & 143.7 & 2.6 \\
\hline 47_Ва.6 & 100 & 0.631 & 3.80 & 0.12 & 146.6 & 2.5 & 146.6 & 2.5 \\
\hline 47_Ba.7 & 125 & 0.690 & 3.23 & 0.09 & 146.5 & 3.5 & 146.5 & 3.5 \\
\hline \multicolumn{9}{|c|}{ JFA $39 B$} \\
\hline \multicolumn{9}{|c|}{$\begin{array}{l}\text { Age: } 14.80 \pm 0.10 \mathrm{ka} \\
\delta^{234} U_{\text {initial }}=146.9 \pm 1.2 \%(159)\end{array}$} \\
\hline $39 \_$B.1 & $360 \#$ & 0.324 & 6.21 & 0.38 & 145.9 & 4.1 & 152.1 & 4.4 \\
\hline 39_B.2 & $280 \#$ & 0.300 & 3.76 & 0.25 & 148.7 & 4.6 & 155.0 & 4.8 \\
\hline 39_B.3 & $360 \#$ & 1.590 & 3.70 & 0.05 & 148.1 & 1.9 & 154.4 & 2.0 \\
\hline 39_B.4 & $800 \#$ & 2.885 & 3.08 & 0.02 & 156.7 & 2.4 & 163.4 & 2.6 \\
\hline \multicolumn{9}{|c|}{$37 \_2$} \\
\hline \multicolumn{9}{|c|}{$\begin{array}{l}\text { Age: } 10.96 \pm 0.10 \mathrm{ka} \\
\delta^{234} U_{\text {initial }}=148.8 \pm 1.1 \% \circ(150)\end{array}$} \\
\hline 37_2_Ba.1 & \# & 0.662 & 2.02 & 0.06 & 154.8 & 4.4 & 159.7 & 4.6 \\
\hline 37_2_-Ba.2 & \# & 0.810 & 4.28 & 0.11 & 144.8 & 1.8 & 149.3 & 1.9 \\
\hline 37_2_Тa.1 & $\#$ & 1.120 & 2.79 & 0.05 & 145.9 & 2.7 & 150.5 & 2.8 \\
\hline $37^{-}{ }^{-}-$Та. 2 & 533 & 1.706 & 4.44 & 0.05 & 141.7 & 1.4 & 146.2 & 1.4 \\
\hline 37_2_Та.3 & 233 & 0.660 & 3.59 & 0.11 & 144.1 & 3.4 & 148.6 & 3.5 \\
\hline 37_2-Тa.4 & 167 & 2.225 & 4.58 & 0.04 & 143.2 & 1.3 & 147.7 & 1.4 \\
\hline 37_2_Тa.5 & 800 & 3.434 & 2.47 & 0.01 & 148.0 & 1.6 & 152.6 & 1.7 \\
\hline 37_2-Тa.6 & 300 & 1.818 & 6.95 & 0.08 & 147.6 & 1.9 & 152.3 & 2.0 \\
\hline 37_2-Та.7 & 200 & 0.496 & 14.99 & 0.60 & 144.0 & 2.6 & 148.5 & 2.8 \\
\hline 37_2- Та.8 & 200 & 0.639 & 2.38 & 0.07 & 149.8 & 4.9 & 154.5 & 5.1 \\
\hline
\end{tabular}

Age: $16.15 \pm 0.14 \mathrm{ka}$

$$
\delta^{234} U_{\text {initial }}=149.1 \pm 1.1 \% \text { (152) }
$$

$\begin{array}{ll}\text { A } & 150 \\ \text { B } & 200 \\ \text { C } & 150 \\ \text { D* } & 200 \\ \text { E } & 350 \\ \text { F } & 200 \\ \text { G } & 250\end{array}$

Age: $43.87 \pm 0.34 \mathrm{ka}$ $\delta^{234} U_{\text {initial }}=144.5 \pm 4.5 \%$ o(144)

W
X
Y
AA
BB
CC

Age: $82.30 \pm 0.68 \mathrm{ka}$

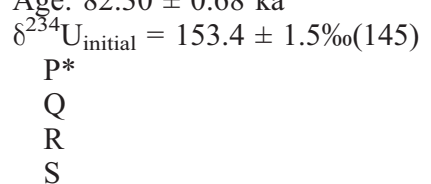

\section{$A L V-3892-1315-001-008$}

$\begin{array}{lllllll}1.691 & 4.80 & 0.11 & 146.2 & 3.5 & 153.0 & 3.7 \\ 1.308 & 3.25 & 0.10 & 145.3 & 4.5 & 152.1 & 4.8 \\ 0.788 & 2.73 & 0.14 & 152.4 & 5.5 & 159.5 & 5.8 \\ 1.307 & 1.91 & 0.06 & 148.2 & 5.2 & 155.1 & 5.5 \\ 2.615 & 2.95 & 0.05 & 141.1 & 3.4 & 147.7 & 3.7 \\ 0.950 & 3.52 & 0.15 & 144.7 & 4.2 & 151.5 & 4.4 \\ 0.720 & 4.74 & 0.26 & 147.0 & 4.7 & 153.9 & 5.0\end{array}$

ALV-3892-1421-002-001-14

$\begin{array}{llllllll}154 & 0.930 & 5.20 & 0.22 & 124.0 & 4.6 & 140.3 & 5.4 \\ 231 & 1.500 & 4.18 & 0.11 & 125.8 & 3.3 & 142.4 & 3.9 \\ 231 & 1.230 & 3.30 & 0.11 & 124.5 & 4.6 & 140.9 & 5.3 \\ 115 & 1.000 & 2.57 & 0.10 & 127.0 & 5.6 & 143.8 & 6.4 \\ 192 & 1.000 & 2.69 & 0.11 & 136.9 & 5.2 & 154.9 & 6.0 \\ 231 & 1.320 & 2.96 & 0.09 & 135.1 & 5.0 & 153.0 & 5.8 \\ 231 & 1.140 & 4.78 & 0.17 & 125.5 & 4.2 & 142.1 & 5.0\end{array}$

ALV-3887-1436-003-007

$\begin{array}{llllllll}148 & 0.720 & 3.65 & 0.20 & 112.9 & 6.7 & 142.4 & 8.7 \\ 148 & 1.170 & 3.79 & 0.13 & 112.9 & 3.8 & 142.4 & 5.0 \\ 148 & 1.060 & 4.07 & 0.15 & 119.9 & 4.0 & 151.3 & 5.4 \\ 148 & 0.950 & 3.46 & 0.15 & 129.0 & 5.3 & 162.7 & 7.0\end{array}$


Table 1. (continued)

\begin{tabular}{|c|c|c|c|c|c|c|c|c|}
\hline \multirow[b]{2}{*}{$\mathrm{T}$} & \multirow{2}{*}{$\begin{array}{l}\text { Width, } \mu \mathrm{m} \\
111\end{array}$} & \multirow{2}{*}{$\begin{array}{l}\text { Weight, mg } \\
0.920\end{array}$} & \multicolumn{2}{|c|}{$[\mathrm{U}], \mathrm{ppm}$} & \multicolumn{2}{|c|}{$\delta^{234} U_{\text {meas }}, \%$} & \multicolumn{2}{|c|}{$\delta^{234} U_{\text {initial }}, \% 0$} \\
\hline & & & 3.50 & 0.15 & 108.4 & 4.4 & 136.8 & 5.8 \\
\hline $\mathrm{U}^{*}$ & 148 & 1.300 & 2.70 & 0.08 & 112.4 & 5.0 & 141.9 & 6.6 \\
\hline V & 185 & 1.460 & 2.62 & 0.07 & 109.7 & 4.6 & 138.4 & 6.0 \\
\hline
\end{tabular}

Age: $218.49 \pm 4.00 \mathrm{ka}$

$\delta^{234} U_{\text {initial }}=152.3 \pm 2.7 \%$ o(162)

$\begin{array}{lllllllll}\mathrm{H} & 200 & 0.960 & 5.56 & 0.23 & 83.4 & 3.4 & 154.6 & 8.2 \\ \mathrm{I} & 200 & 1.410 & 4.52 & 0.13 & 81.0 & 4.7 & 150.2 & 10.5 \\ \mathrm{~J} & 200 & 1.510 & 3.34 & 0.09 & 82.0 & 4.9 & 152.1 & 11.0 \\ \mathrm{~K} & 200 & 1.190 & 2.40 & 0.08 & 95.0 & 5.1 & 176.1 & 11.5 \\ \mathrm{~L} & 150 & 0.990 & 2.57 & 0.10 & 119.1 & 6.7 & 220.8 & 15.0 \\ \mathrm{M} & 150 & 1.100 & 2.27 & 0.08 & 93.5 & 7.5 & 173.4 & 16.0 \\ \mathrm{~N} & 250 & 1.110 & 2.62 & 0.09 & 82.4 & 4.3 & 152.7 & 9.7 \\ \mathrm{O} & 250 & 0.960 & 3.04 & 0.13 & 82.8 & 4.1 & 153.6 & 9.4\end{array}$

${ }^{a}$ For each coral the sample name and whole coral age and $\delta^{234} U_{\text {initial }}$ are tabulated. The number in parentheses is the weight and [U] averaged $\delta^{234} U_{\text {initial }}$ value calculated from the micro-milled samples. Differences between these two numbers are controlled by the diagenetic processes described in the discussion. Samples marked with a \# targeted discrete areas within coral sections and so are not suited to modeling the evolution of the $\mathrm{U}$ series isotopes. All errors are 2 s.e. Starred [U] subsamples may have lost powder while transferring from weighing to dissolution vials and therefore will have an inaccurate, low [U].

and have a typical range of 2.5-5.5 ppm (Table 1). Endolithic sponge borings in the $11 \mathrm{ka}$ coral have a brown discoloration (Figure 2) and a measured [U] of $15 \mathrm{ppm}$. No bioeroded samples were analyzed using fission tracks, so we do not know the microscale spatial distribution of uranium within such bioeroded areas. Whole-coral [U] range from $2.3-7.0 \mathrm{ppm}$ with an average of $3.9 \mathrm{ppm}$ and there is no correlation between the age of the sample and the $[\mathrm{U}]$.

[16] Micromilled corals were analyzed for $\delta^{234} U$ as well as [U]. The integrated $\delta^{234} \mathrm{U}$ of the modern, micromilled coral averages $145 \pm 2.2 \%$, identical to the seawater value (Figure 7). By contrast, individual micromilled coral samples display a wide range of ${ }^{234} U_{\text {initial }}$ values, from $137-221 \%$ (Table 2). Whole fossil coral analyses have a similar $\delta^{234} U_{\text {initial }}$ range, $138-210 \%$ (Figure 7). The same data are plotted with distance along the coral perpendicular to the banding to show the spatial distribution of [U] and $\delta^{234} \mathrm{U}_{\text {initial }}$ for five of the micromilled fossil corals (Figure 8). The highest $\delta^{234} U_{\text {initial }}$ is observed in the central band for three out of four septal samples. In the thecal sample, the highest $\delta^{234} U_{\text {initial }}$ values are also observed in the dark bands, except where the coral has been subjected to boring. The $\delta^{234} U_{\text {initial }}$ from the average of the micro-milled samples for two corals (44 ka and $82 \mathrm{ka}$ ) are not elevated above seawater. However, they both show internal variability, with ranges of $140-155 \%$ and $137-163 \%$, respectively. The $11 \mathrm{ka}, 16 \mathrm{ka}$ and $218 \mathrm{ka}$ sections have average $\delta^{234} U_{\text {initial values and micromilled }}$ ranges of $150 \%$ (146-160\%o), 152\%o (148$159 \%$ ) and $162 \%$ (150-221\%o), respectively.

\section{Discussion}

[17] We use the evidence of coherent, primary [U] heterogeneity coupled with development of $\delta^{234} U_{\text {initial }}$ gradients over time to model the internal, closed-system processes that affect the distribution of $U$ and $T h$ within the carbonate structure. These processes are radioactive decay, direct transfer of alpha-recoil decay products and diffusion. With no net loss or gain of $U$ or Th, the age and $\delta^{234} U_{\text {initial }}$ of the whole coral will not be affected. We then investigate open-system behavior that does have the potential to alter the apparent whole-coral age.

[18] We test the sensitivity of these diagenetic processes using a simple box model applied to an "artificial" coral (Figure 9). This artificial coral has 25 parallel $50 \mu \mathrm{m}$-width boxes whose initial boundary conditions reflect our modern observations, i.e., $[\mathrm{U}]$ distribution lower in the centre than the edges, a uniform $\delta^{234} U_{\text {initial }}$ of 146 and $\left[{ }^{230} \mathrm{Th}\right]$ of zero (Figure 9). Each isotope ${ }^{238} \mathrm{U},{ }^{230} \mathrm{Th},{ }^{234} \mathrm{U}^{1}$ $\left({ }^{234} \mathrm{U}\right.$ present in the primary coral structure) and ${ }^{234} \mathrm{U}^{\mathrm{AR}}\left({ }^{234} \mathrm{U}\right.$ produced by decay $)$ is considered separately. The model is run for $20 \mathrm{kyr}$ and $200 \mathrm{kyr}$ to investigate the cumulative effects of each pro- 

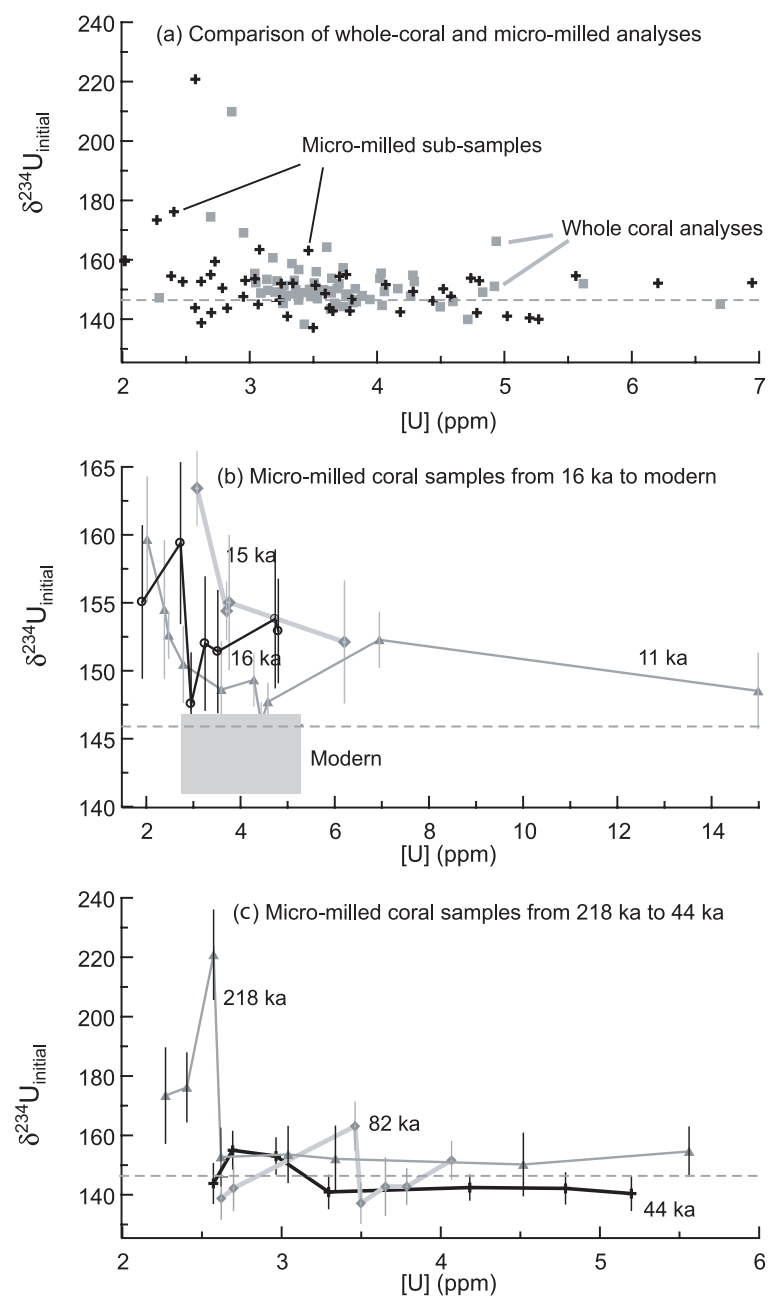

Figure 7. U concentration (ppm) plotted against $\delta^{234} U_{\text {initial }}(\%)$ for all deep sea corals analyzed in this study. Uncertainties are 2 s.e. for $\delta^{234} U_{\text {initial and are }}$ within the symbol size for [U]. Figure 7a compares analyses made on whole chunks of coral (Table 2) to the micromilled slices in Table 1. The similarity of the two distributions is suggestive of the same processes being responsible on both $0.1-10 \mathrm{~mm}$ scales. Figures $7 \mathrm{~b}$ and $7 \mathrm{c}$ show the micromilled data in more detail. Figure $7 \mathrm{~b}$ displays the individual measurements of corals of $11 \mathrm{ka}$, $15 \mathrm{ka}$, and $16 \mathrm{ka}$ together with the modern coral plotted as the total range of [U] and the average $\delta^{234} \mathrm{U}_{\text {initial }}$ with a 2 s.d. range. Figure $7 \mathrm{c}$ shows the distribution in the oldest three corals, $44 \mathrm{ka}, 82 \mathrm{ka}$, and $218 \mathrm{ka}$. In all cases the dashed horizontal line represents the modern seawater value. The half-lives used to calculate activities from ${ }^{230} \mathrm{Th}$ and ${ }^{234} \mathrm{U}$ are from Cheng et al. [2000b].

cess over the timescales of interest. The sensitivity study results are plotted as $\delta^{234} U_{\text {initial }}$ versus [U] so that the low [U] boxes plot the left and the high [U] boxes plot to the right (Figures 10a-10d). The model is then tested on five real coral sections that exhibit both closed and open-system $U$ series systematics.

\subsection{Closed-System U and Th Processes}

\subsubsection{Radioactive Decay and Alpha Recoil}

[19] The most obvious closed-system process is radioactive decay, governed by the activity of the isotopes. The energy produced by an alpha decay gives recoil momentum to the alpha particle and also to the daughter isotope, which has an expected recoil length scale $\left(\mathrm{L}_{\mathrm{R}}\right)$ on the order $0.1 \mu \mathrm{m}$ [Kigoshi, 1971]. The amount of ${ }^{234} \mathrm{Th}$ and ${ }^{230} \mathrm{Th}$ that is affected by recoil-momentum is controlled by the activity of the respective parent isotopes ${ }^{238} \mathrm{U}$ and ${ }^{234} \mathrm{U}$, and the distance is controlled by the recoil length scale. Since we know both the length scale of the recoil $\left(\mathrm{L}_{\mathrm{R}}\right)$ and the primary [U] heterogeneity we can calculate the magnitude of isotopic variability that should be produced by direct recoil transfer. Recoil-momentum has a random directionality, so the model allows only a quarter of the decays within the recoil length scale to escape to the neighboring box. Equation (1) describes the direct alpha-recoil flux in and out $\left(F_{\alpha_{-} r}^{i n}\right.$ and $F_{\alpha_{-} r}^{o u t}$ ) of a box " $\mathrm{j}$ " of length $\mathrm{L}_{\mathrm{B}}$.

$$
\begin{aligned}
\frac{d N^{j}}{d t} & =F_{\alpha \_r}^{\text {in }}-F_{\alpha \_r^{r}}^{\text {out }} \\
& =0.25 \lambda_{\text {parent }} \frac{L_{R}}{L_{B}}\left[-2 N_{\text {parent }}^{j}+N_{\text {parent }}^{j-1}+N_{\text {parent }}^{j+1}\right]
\end{aligned}
$$

The net transfer of ${ }^{230} \mathrm{Th}$ and ${ }^{234} \mathrm{Th}$ is dependent on the ${ }^{238} \mathrm{U}$ and ${ }^{234} \mathrm{U}$ concentration gradient and leads to elevated $\delta^{234} \mathrm{U}_{\text {initial }}$ in low [U] zones as observed in the coral sections. However, the 500-fold disparity between recoil length scale and sampling length scale means that direct transfer only produces sub-per mil $\delta^{234} U_{\text {initial }}$ deviations even after 200 kyr (Figure 10a). This is not a strictly closed-system process because daughter isotopes can be expelled from the edges of the coral, but the small number of atoms expelled has a negligible effect on the whole-coral $\delta^{234} \mathrm{U}_{\text {initial }}$ or age.

\subsubsection{Diffusion}

[20] The presence of [U] gradients may lead to diffusive movement of uranium. The diffusion coefficients for solid-state diffusion of $\mathrm{Sr}$ and $\mathrm{Pb}$ in calcite at $300 \mathrm{~K}$ are $\sim 2 \times 10^{-24} \mu^{2} \mathrm{yr}^{-1}$ and 2

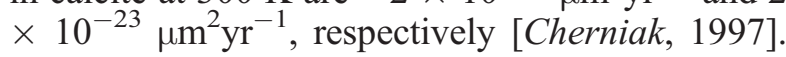
Uranium is likely to be of a similar magnitude, and may be even slower if it diffuses as a hexavalent carbonate complex in aragonite. Solid-state diffu- 
葡

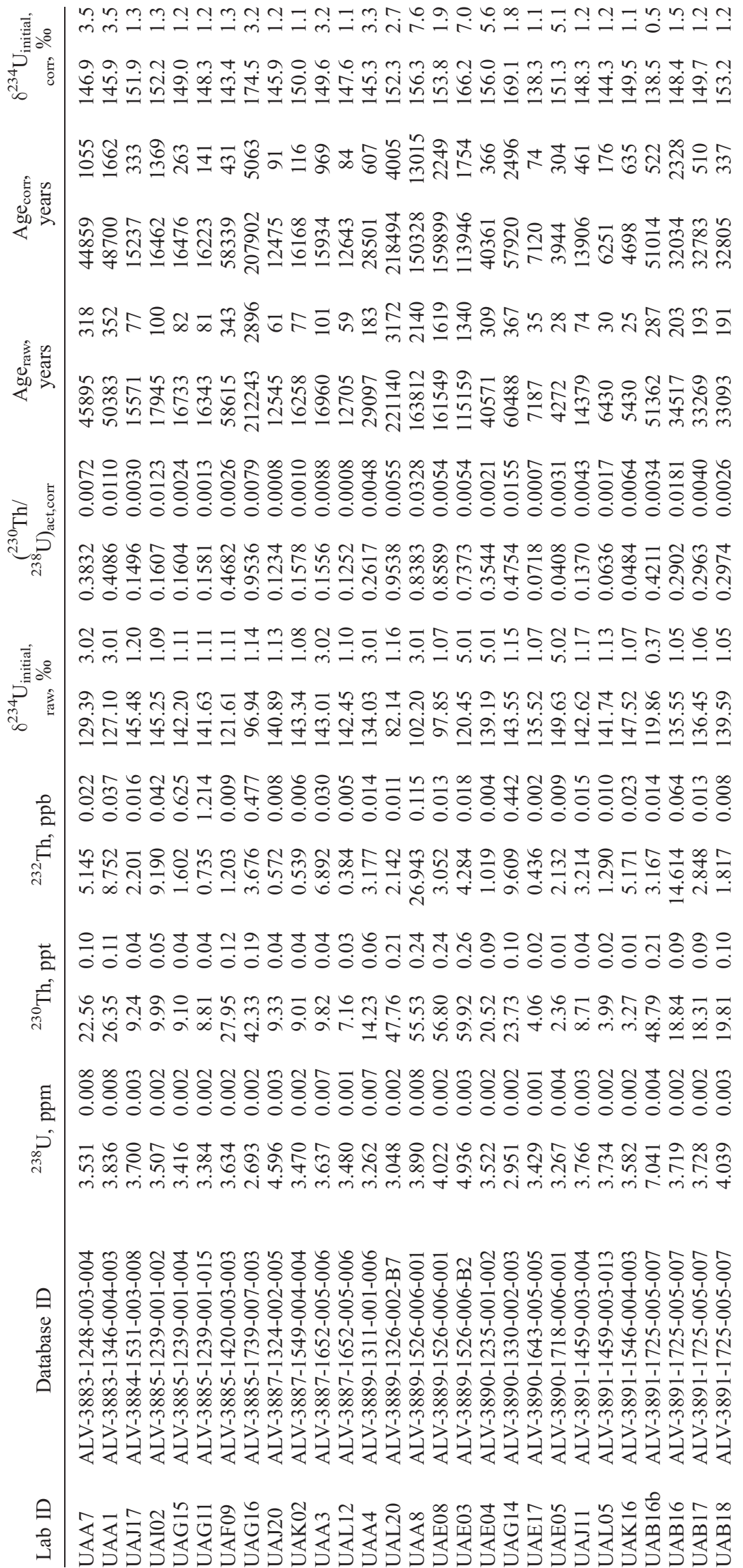


sion of $U$ through the crystal lattice is therefore expected to be negligible on $10^{4}-10^{5}$ year timescales. Although the fossil data do show a reduced [U] contrast relative to modern corals, the boundaries retain their sharpness, unlike typical diffusive profiles (Figure 6). The slow expected rate of diffusion for lattice-bound $U$, and the retention of sharp boundaries suggest that diffusion of primary $\mathrm{U}$ is not an important process. In addition, simultaneous diffusion of ${ }^{234} \mathrm{U}$ and ${ }^{238} \mathrm{U}$ cannot explain the build up of isotopic gradients.

[21] If ${ }^{238} \mathrm{U}$ and all, or some of, the ${ }^{234} \mathrm{U}$ have different apparent diffusion coefficients then we would expect to see isotopic gradients develop. The recoil energy given to the ${ }^{234} \mathrm{Th}$ daughter from a ${ }^{238} \mathrm{U}$ decay is sufficient to displace it from its lattice site, in many cases to an interstitial location. Thus the ${ }^{234} \mathrm{U}^{\mathrm{AR}}$ that has been produced through decay from ${ }^{234} \mathrm{Th}$ is likely to be more mobile than its parent [Fleischer, 1988]. This process can lead to a situation whereby ${ }^{234} \mathrm{U}^{\mathrm{AR}}$ has a faster diffusion coefficient than ${ }^{238} \mathrm{U}$, hereinafter referred to as alpha-recoil diffusion. In the model, ${ }^{234} \mathrm{U}^{\mathrm{AR}}$ is allowed to move diffusively but ${ }^{238} \mathrm{U}$ and ${ }^{234} \mathrm{U}^{\mathrm{i}}$ are not. As a result ${ }^{234} \mathrm{U}^{\mathrm{Ar}}$ atoms move down the concentration gradient causing build up of ${ }^{234} \mathrm{U}^{\mathrm{AR}}$ in the low [U] central band, with ${ }^{234} \mathrm{U}^{\mathrm{AR}}$ depletion in the boxes that are immediately adjacent (Figure 10b).

[22] We can estimate the diffusion coefficients $\left(D^{A R}\right)$ by considering the rate of $U$ movement in other systems, and by tuning the model to generate the observed $\delta^{234} U_{\text {initial }}$ ranges. The rate of diffusion in sedimentary pore fluids is $\sim 100 \mu \mathrm{m}^{2} \mathrm{yr}^{-1}$ [Li and Gregory, 1974] and ranges from $\sim 5-$ $120 \mu^{2} \mathrm{yr}^{-1}$ in ferromanganese crusts [Henderson and Burton, 1999]. These rates are both many orders of magnitude greater than solid-state diffusion and suggest a mechanistic role for pore fluids (water has a diffusion coefficient of $\sim 1000 \mu^{2} \mathrm{yr}^{-1}$ [Li and Gregory, 1974]). An alternate rapid diffusive pathway is along grain boundaries. Variable grain size or porosity are both therefore likely to affect the extent of alpha-recoil diffusion. We take the simple approach of assigning a separate diffusion coefficient to each mineral

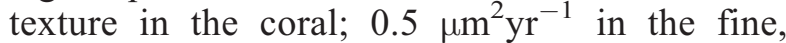
granular aragonite and the slower rate of $0.1 \mu^{2} \mathrm{yr}^{-1}$ in the larger-grained acicular material. These coefficients are within $10^{4}$ of the diffusivity of water, but are more than $10^{20}$ times faster than solid-state diffusion reflecting the role of interstitial fluids in controlling the movement of ${ }^{234} \mathrm{U}^{\mathrm{AR}}$. In 

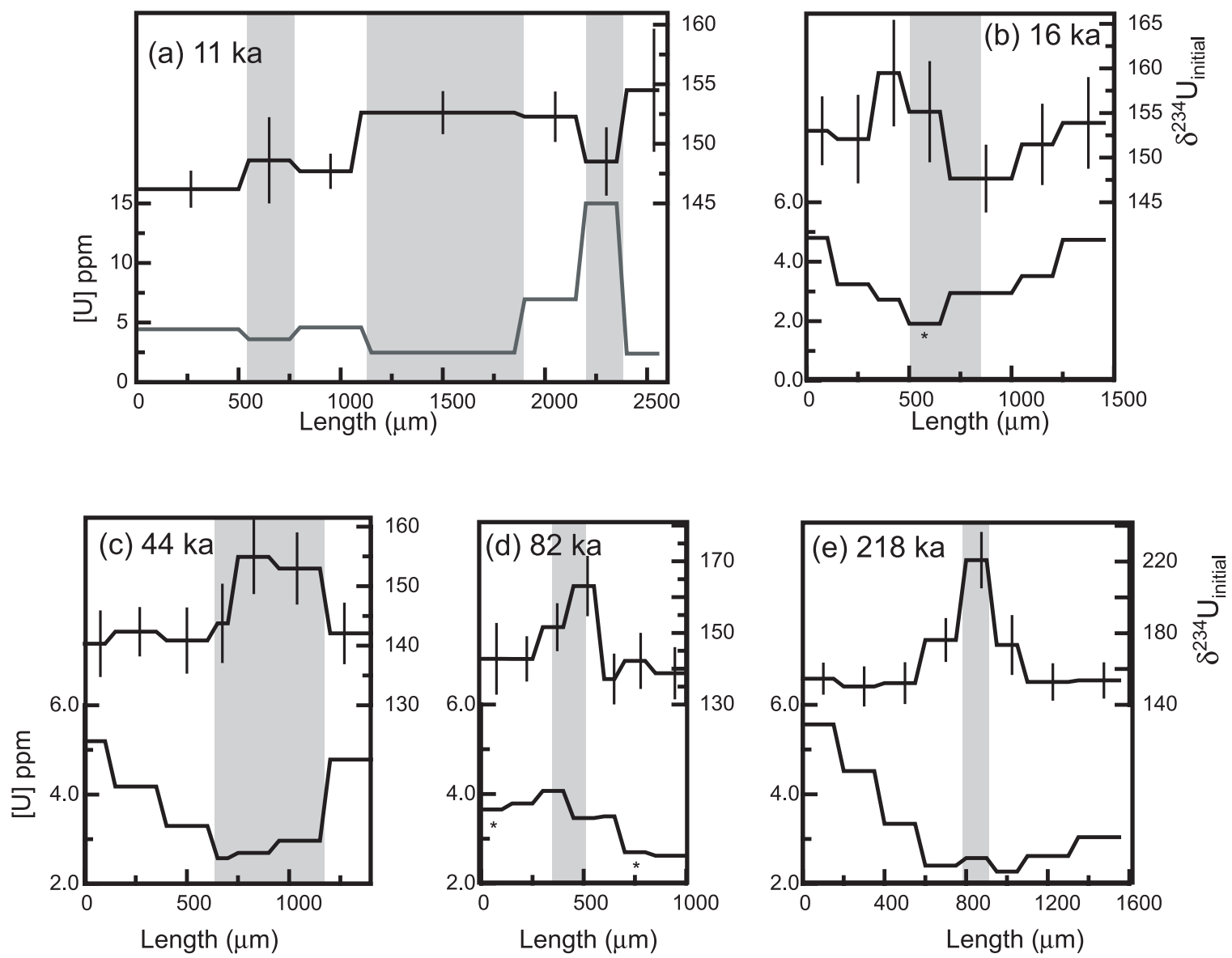

Figure 8. Arranged in order of increasing age, Figures $8 \mathrm{a}-8 \mathrm{e}$ show the measured spatial distribution of $\delta^{234} \mathrm{U}_{\text {initial }}$ and $[\mathrm{U}]$ for five different corals. Figure 8a is a thecal sample (as shown in Figure 2b), and the remaining four samples are septal. Error bars for $\delta^{234} U_{\text {initial }}$ are 2 s.e. Starred [U] subsamples may have lost powder while transferring from weighing to dissolution vials and therefore will have an inaccurate, low [U]. The gray shading represents the area of the coral that consists of fine-grained aragonite.

the sensitivity test, these diffusion coefficients produce maximum $\delta^{234} U_{\text {initial }}$ values of $151 \%$ after $20 \mathrm{kyr}$ and 458\%o after $200 \mathrm{kyr}$ (Figure 10b).

[23] The presence of [U] gradients can lead to large within-coral isotopic gradients, not just for $\delta^{234} \mathrm{U}_{\text {initial }}$ but also for $\left({ }^{230} \mathrm{Th} /{ }^{238} \mathrm{U}\right)$. These two ratios are used to calculate the age of the sample, and so these closed-system processes can have important effects on the accuracy of the apparent U-Th age. Of course, if the entire coral sample is dissolved and analyzed, an accurate age with a seawater $\delta^{234} U_{\text {initial }}$ will be determined. However, if the sampling is biased toward one specific part of the coral, the resulting age may be inaccurate. For example, in the 200 kyr sensitivity study, alpha-recoil diffusion leads to apparent ages of individual boxes that range from $157 \mathrm{ka}$ to $213 \mathrm{ka}$. The apparent age will be a function of the proportion of each box sampled, but biases of thousands of years are not unreasonable.

\subsubsection{Two Corals Affected by Closed-System Diagenesis}

[24] Two measured fossil coral sections, $44 \mathrm{ka}$ and $82 \mathrm{ka}$, do not exhibit whole-coral $\delta^{234} \mathrm{U}_{\text {initial }}$ elevation, and so the $\delta^{234} \mathrm{U}_{\text {initial }}$ variability in the micromilled samples is likely to be a result of internal reorganization of $U$ and $T h$. Therefore we model both corals by allowing decay, direct transfer of alpha-decay products and alpha-recoil diffusion with $\mathrm{D}^{\mathrm{AR}}$ values of $0.5 \mu \mathrm{m}^{2} \mathrm{yr}^{-1}$ and $0.1 \mu \mathrm{m}^{2} \mathrm{yr}^{-1}$ in the granular and acicular aragonite, respectively (Figures 11a and 11b). The initial [U] is set by the micromilled measurements, and each sample is divided in to $50 \mu \mathrm{m}$ slices, resembling the sensi- 

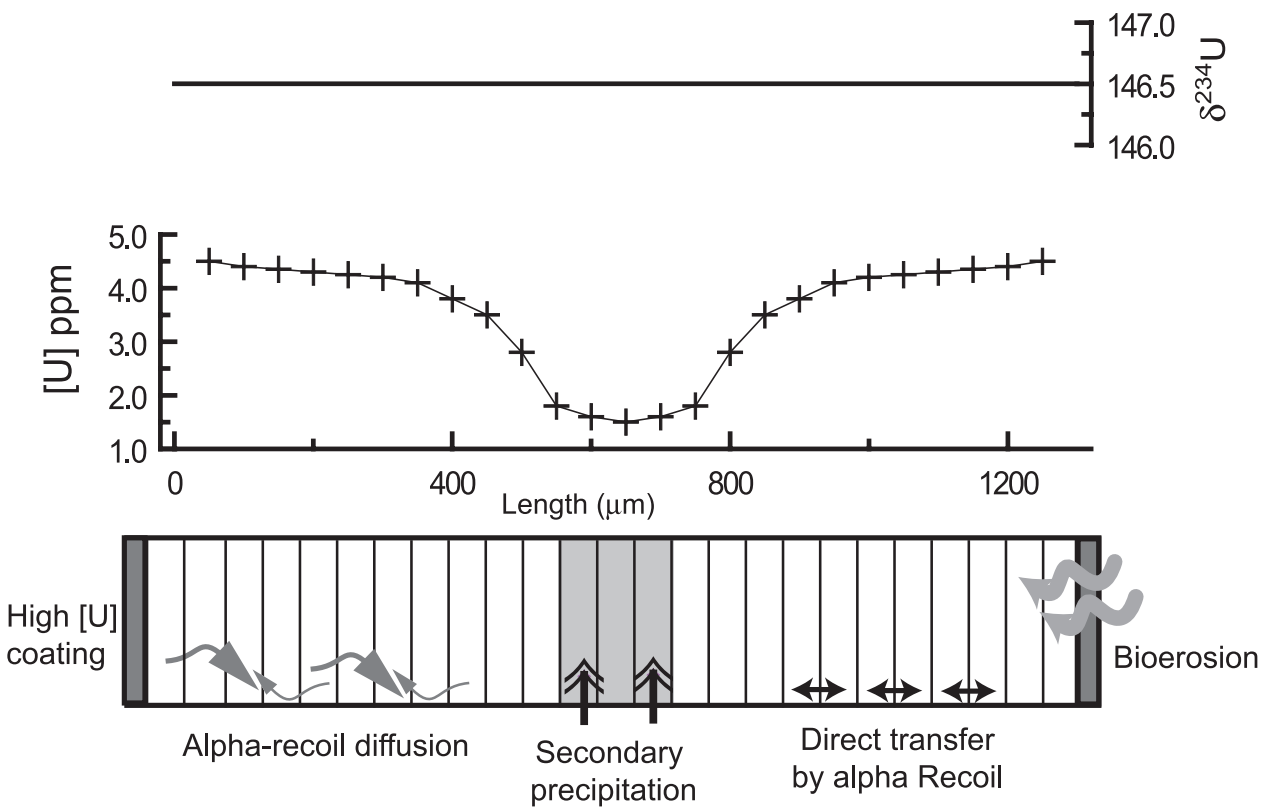

Figure 9. Schematic diagram of the initial boundary conditions of the "artificial" coral section used to test the sensitivity of each diagenetic process. The model is divided into 25 boxes of $50 \mu \mathrm{m}$ width. The three central boxes, shaded light gray, represent fine-grained irregular aragonite, and the white boxes represent the acicular crystals. The outermost dark gray area is representative of a high $(6 \mathrm{ppm})[\mathrm{U}]$ coating, such as an organic film. In addition to radioactive decay, five processes are modeled: bioerosion, secondary precipitation, "diffusion," direct transfer of alpha-recoil ${ }^{230} \mathrm{Th}$ and ${ }^{234} \mathrm{Th}$, and alpha-recoil diffusion. ${ }^{230} \mathrm{Th}$ is not subject to alpha-recoil diffusion because Th is much less mobile than $\mathrm{U}$ in this type of environment.
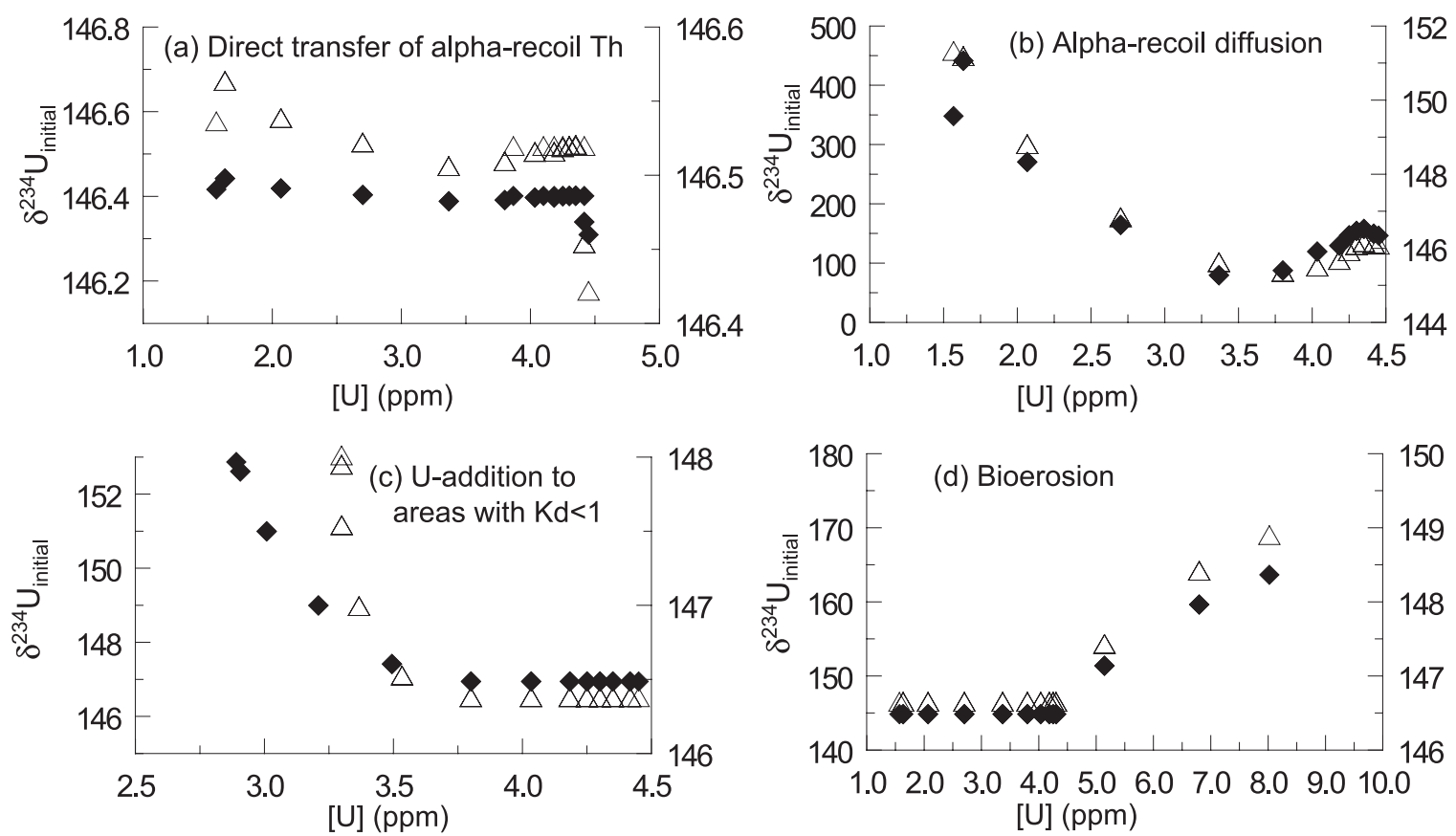

Figure 10. Four model scenarios run for $20 \mathrm{ka}$ (diamonds, right-hand axes) and $200 \mathrm{ka}$ (triangles, left-hand axes) demonstrate the sensitivity of $\delta^{234} \mathrm{U}_{\text {initial }}$ and age for each of the processes described in the text and shown in Figure 9. The model results are displayed as $\delta^{234} U_{\text {initial }}$ versus [U] to allow comparison with the measurements shown in Figure 7. The separate plots show (a) direct transfer of ${ }^{230} \mathrm{Th}$ and ${ }^{234} \mathrm{Th}$ by alpha recoil, (b) alpha-recoil diffusion, (c) secondary precipitation, and (d) addition of $\mathrm{U}$ by bioerosion. 

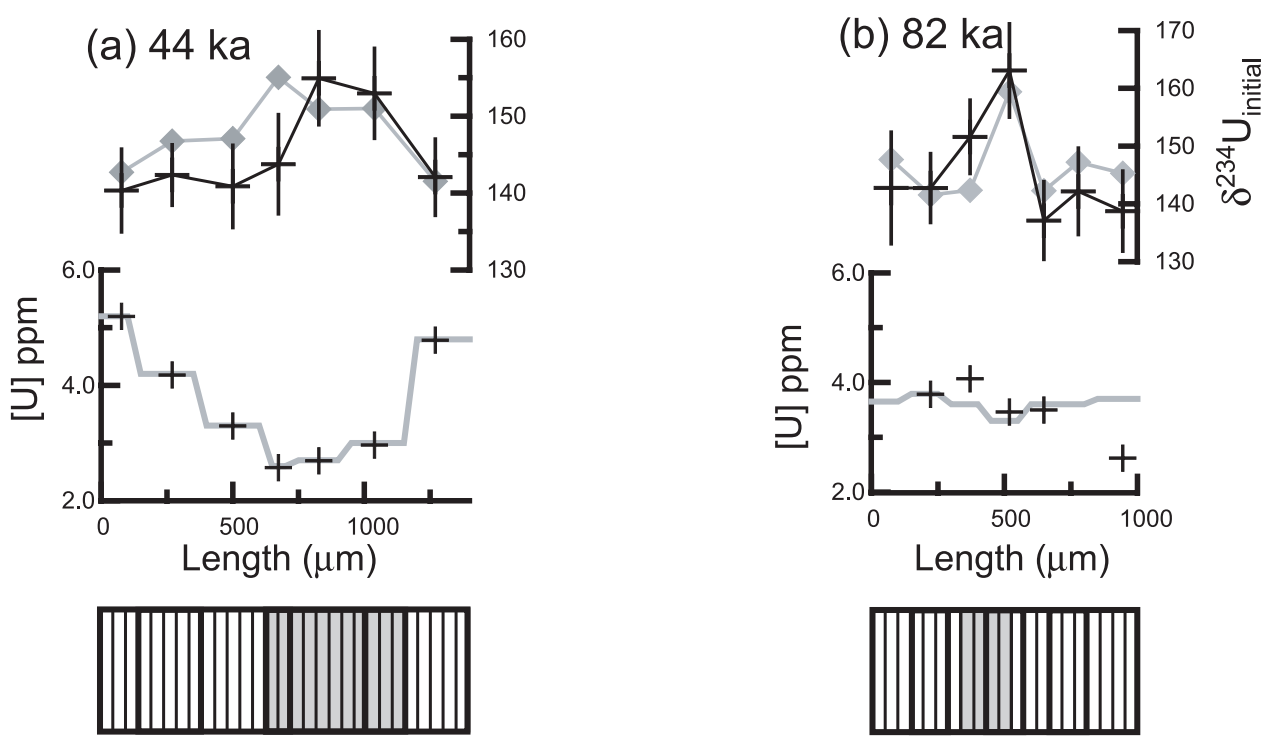

Figure 11. Application of the closed-system $U$ diagenesis model to two coral sections that have a seawater $\delta^{234} \mathrm{U}_{\text {initial. }}$. These processes are radioactive decay, direct transfer of ${ }^{230} \mathrm{Th}$ and ${ }^{234} \mathrm{Th}$ by alpha recoil, and alpha-recoil diffusion of ${ }^{234} \mathrm{U}^{\mathrm{AR}}$. Gray and white areas in the schematic coral sections represent areas of granular and acicular aragonite, respectively. Black crosses are data with 2 s.e. error bars which are smaller than the symbol size for [U]. Gray diamonds in each of the upper plots are the model output using the [U] boundary conditions shown by the gray line in the lower plot.

tivity study. The equation for each isotope follows the form

$$
\begin{aligned}
& \frac{d N_{238}}{d t}=-\lambda_{238} N_{238} \\
& \frac{d N_{234}^{i}}{d t}=-\lambda_{234} N_{234}^{i} \\
& \begin{aligned}
\frac{d N_{234}^{A R}}{d t}= & \lambda_{238} N_{238}-\lambda_{234} N_{234}^{A R}+\left(\frac{d}{d z} D^{A R} \frac{d N_{234}^{A R}}{d z}\right)+F_{\alpha \_r}^{i n-4} \\
& -F_{\alpha \_r}^{\text {out }-4}
\end{aligned} \\
& \frac{d N_{230}}{d t}=\lambda_{234} N_{234}^{i}+\lambda_{234} N_{234}^{A R}-\lambda_{230} N_{230}+F_{\alpha\lrcorner^{*}}^{\text {in } \_0}-F_{\alpha\lrcorner^{\prime}}^{\text {out } 0}
\end{aligned}
$$

The $44 \mathrm{ka}$ coral model results are remarkably similar to the observations, both spatially and in total $\delta^{234} U_{\text {initial }}$ range (Figure 12a). During sampling of the $82 \mathrm{ka}$ coral we did not achieve $100 \%$ recovery on some of the powder samples, leading to inaccurate [U] (Table 2), so the initial boundary conditions are not as well constrained in this sample. However, assuming a reasonable [U] distribution and applying the model returns a spatial pattern and $\delta^{234} \mathrm{U}_{\text {initial }}$ range that is, again, very similar to the observations (Figure 11b). This test of the model confirms that the closed-system processes of decay, direct alpha-recoil transfer and alpha-recoil diffusion are important in controlling $\mathrm{U}$ distribution within a single coral.

\subsection{Open-System Behavior}

[25] There is clear evidence of open-system behavior in our sample set from fission tracks, micromilling and whole-coral analyses. In the following discussion we investigate the effects of adding uranium via three distinct mechanisms. The first two of these mechanisms add ${ }^{238} \mathrm{U}$ and ${ }^{234} \mathrm{U}$ simultaneously with a seawater $\delta^{234} U$. FX ${ }^{\mathrm{pptn}}$ represents $U$ addition to areas that were precipitated with a distribution coefficient lower than 1 and $\mathrm{FX}^{\mathrm{org}}$ represents $\mathrm{U}$ added by bioerosion. The third mechanism adds only ${ }^{234} \mathrm{U}$, and is a direct extension of the process of alpha-recoil diffusion. We use the artificial coral to investigate the sensitivity of the $\delta^{234} U_{\text {initial }}$ to each process, and then we test the model on three real coral sections. One difficulty when testing the model is setting the initial [U] boundary conditions if uranium is being added at an unknown rate over time. Fission track data show that the contrast between the minimum and maximum $[\mathrm{U}]$ is reduced from a factor of $>3$ to $\sim 2$ over $33 \mathrm{ka}$, but we do not know how rapidly this process takes place. In all micromilled samples from modern back to $218 \mathrm{ka}$ this contrast is approximately a factor of 2 , which reflects, in part, 

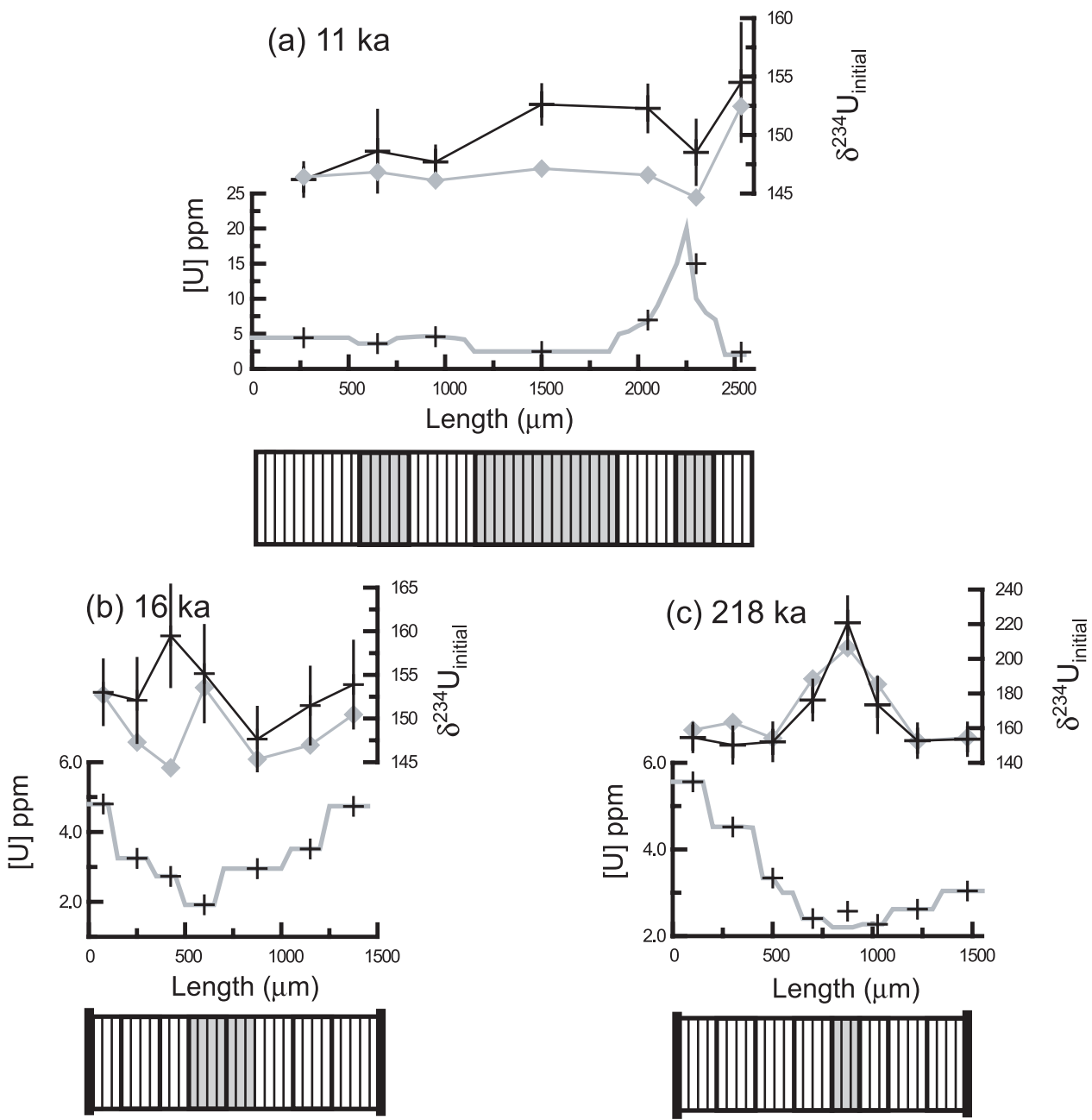

Figure 12. Application of the $U$ diagenesis model to the three corals that have elevated $\delta^{234} U_{\text {initial }}$ values. The model allows radioactive decay, direct transfer of ${ }^{230} \mathrm{Th}$ and ${ }^{234} \mathrm{Th}$ by alpha recoil, and alpha-recoil diffusion of ${ }^{234} \mathrm{U}^{\mathrm{AR}}$. Black bars on Figures $12 \mathrm{~b}$ and $12 \mathrm{c}$ represent high [U] surface coatings. Gray and white areas in the schematic coral sections represent areas of granular and acicular aragonite, respectively. Heavy lines delimit the physical sampling of the coral. Black crosses are data with 2 s.e. error bars which are smaller than the symbol size for [U]. Gray diamonds in each of the upper plots are the model output using the [U] boundary conditions shown by the gray line in the lower plot.

the inherent bias when microsampling across several $100 \mathrm{~s} \mu \mathrm{m}$, but may also reflect early $\mathrm{U}$ addition. Shallow-water coral studies have shown rapid diagenetic pathways for U [Swart and Hubbard, 1982] so we assume that $U$ addition takes place soon after death and use the measured [U] concentrations for setting the initial boundary conditions.

\subsubsection{Simultaneous Addition of ${ }^{234} U$ and ${ }^{238} \mathrm{U}$}

[26] When the coral calcifies it controls the [U] of the aragonite, a so-called vital effect. The resulting low [U] central band has a $\mathrm{Kd}<1$, which we assume to be out of thermodynamic equilibrium.
The flux $\mathrm{FX}^{\mathrm{pptn}}$ acts to redress this disequilibrium and leads to a reduction in the difference between the maximum and minimum [U], a trend observed in our fission track data. Possible mechanisms for this flux are secondary precipitation and re-mineralization. $F X^{\text {pptn }}$ is modeled as a $U$ flux $\left(f_{p p t n}\right)$ that is scaled to the difference between $\mathrm{U} / \mathrm{Ca}_{\text {seawater }}$ and $\mathrm{U} / \mathrm{Ca}_{\text {aragonite }}$ assuming that the process moves toward a $\mathrm{Kd}_{\text {inorganic }}$ of 1 :

$$
F X^{\text {pptn }}=f_{\text {pptn }}\left(K d_{\text {inorganic }}-K d_{\text {coral }}\right)
$$

If the uranium is added continually over the diagenetic history of the coral, then $\delta^{234} U_{\text {initial }}$ 
gradients develop, with elevated $\delta^{234} \mathrm{U}_{\text {initial }}$ associated with low initial [U] (Figure 10c). However, the maximum changes of $\sim 2 \%$ after $20 \mathrm{kyr}$ and $7 \%$ after $200 \mathrm{kyr}$ in the low [U] bands are much lower than the typical changes observed in the data (Figure 7). The corresponding whole-coral $\delta^{234} U_{\mathrm{i}-}$ initial values are even lower, $<1 \%$ in both cases. Even in the extreme case of $100 \%$ replacement of the primary uranium at the time of collection, this type of $U$ addition cannot account for the full extent of $\delta^{234} U_{\text {initial }}$ elevations observed in those corals whose measured $\delta^{234} U$ lies above the modern seawater value (Figure 1). However, this process may be important in driving the reduction in $[\mathrm{U}]$ contrast observed between modern and fossil corals.

\subsubsection{Bioerosion}

[27] We observe numerous endolithic borings in fossil deep-sea corals that leave a brown colored residue probably containing organic matter (Figure 2). Organic matter can have a [U] of up to 70 ppm [Amiel et al., 1973] so even 1\% residual organic matter can cause $>20 \%$ increase in the measured $[\mathrm{U}]$. Bioerosional features can produce much greater $[\mathrm{U}]$ values than $\mathrm{FX}^{\mathrm{pptn}}$. Since the timing of bioerosion is unknown, the model uses a continuous flux of $\mathrm{FX}^{\text {org }}$ to the two outermost boxes, with $\mathrm{FX}^{\mathrm{org}} / 2$ to the two adjacent interior boxes. $\mathrm{FX}^{\mathrm{org}}$ rates of $1 \times 10^{-12} \mathrm{~mol} / \mathrm{yr}(20 \mathrm{ka})$ and $1 \times 10^{-13} \mathrm{~mol} / \mathrm{yr}(200 \mathrm{ka})$ generates maximum [U] of $\sim 8 \mathrm{ppm}$ (Figure 10d). Uranium addition through continuous bioerosion causes the apparent calculated ages to be younger than the "real" age since the $\left({ }^{230} \mathrm{Th} /{ }^{238} \mathrm{U}\right)$ is reduced by the addition of ${ }^{238} \mathrm{U}$. For these two model runs we calculate apparent ages of $18.6 \mathrm{ka}$ and $179 \mathrm{ka}$, an inaccuracy of $\sim 7 \%$ and $11 \%$ from the true ages. The whole-coral $\delta^{234} U_{\text {initial }}$ values reach values of $147 \%$ ( $20 \mathrm{ka})$ and $154 \% 0(200 \mathrm{ka})$, but the zones of $\delta^{234} \mathrm{U}_{\text {initial }}$ elevation are associated with high $[\mathrm{U}]$, which is inconsistent with our detailed observations (Figure 10d).

[28] Early bioerosion will not have such a large impact on the apparent age, but the associated change in the [U] distribution may have important implications for the $\delta^{234} U_{\text {initial }}$ pattern when alpharecoil diffusion is taken into account. For example, the $11 \mathrm{ka}$ coral has clearly been bioeroded, and has associated [U] concentrations of up to $15 \mathrm{ppm}$ (Figures 2 and 7). The samples next to the high [U] zone have the highest $\delta^{234} \mathrm{U}_{\text {initial, }}$, suggesting that the bioerosion occurred early in the post-mortem history as there has been sufficient time for ${ }^{234} \mathrm{U}^{\mathrm{AR}}$ to move through the coral from the high [U] area (Figure 8a). We use the internal reorganization processes and a high [U] initial condition in the bioeroded zone to model the $11 \mathrm{ka}$ coral, and produce an isotopic pattern consistent with the observations (Figure 12a). The modeled $\delta^{234} \mathrm{U}_{\text {initial }}$ values are lower than the measured data indicating the presence of an external source of ${ }^{234} \mathrm{U}$ to the coral.

\subsubsection{Addition of ${ }^{234} \mathrm{U}$ without ${ }^{238} \mathrm{U}$}

[29] The process of alpha-recoil diffusion alone results in $\delta^{234} U_{\text {initial }}$ depletion at the high [U] end of a concentration gradient; however in some samples this depletion is not observed. For example, at both edges of the $16 \mathrm{ka}$ septa, the outermost boxes have the highest $[\mathrm{U}]$ and a $\delta^{234} \mathrm{U}_{\text {initial }}$ greater than the adjoining box and the same observation is true for one side of the $218 \mathrm{ka}$ coral (Figures $8 \mathrm{~b}$ and $8 \mathrm{e}$ ). Moreover, both of these examples display whole-coral $\delta^{234} U_{\text {initial }}$ values greater than seawater, indicative of $U$ addition. These two observations indicate that there is an external source of ${ }^{234} \mathrm{U}$, potentially from a high [U] surface layer. Most fossil corals are coated in a thin black/brown ferromanganese layer, and ferromanganese nodules typically have high $[\mathrm{U}]$ concentrations $>10 \mathrm{ppm}$ [Henderson and Burton, 1999; Neff et al., 1999]. However, the coatings associated with deep-sea corals have much lower [U] ranging from 2.96.1ppm [Lomitschka and Mangini, 1999; Cheng et al., 2000a; Schroder-Ritzrau et al., 2003]. The associated corals display the slightly lower range of $1.6-5.1 \mathrm{ppm}$ giving rise to $[\mathrm{U}]_{\text {crust }} /[\mathrm{U}]_{\text {coral }}$ ratios of 0.8 to 2.2. The crusts therefore may act as a source of ${ }^{234} U$ in some instances, but not in others. An alternate source is U-rich organic matter which is likely to be present as a thin veneer between the coral and the ferromanganese coating.

[30] We model ${ }^{234} \mathrm{U}$ addition from a surface layer with a [U] of $6 \mathrm{ppm}$, and allow alpha-recoil diffusion between the surface layer and the coral with a coefficient of $0.1 \mu \mathrm{m}^{2} \mathrm{yr}^{-1}$. We then calculate an apparent age and $\delta^{234} U_{\text {initial }}$ for the coral excluding the high [U] surface layer. This "sampling" is done to mimic the physical cleaning procedure that removes the exterior surface from real corals. The model sensitivity run results in a similar spatial pattern as alpha-recoil diffusion alone (Figure 10b), but the edges have a higher $\delta^{234} U_{\text {initial }}$. The final, whole-coral $\delta^{234} \mathrm{U}_{\text {initial }}$ values of $147 \% 0(20 \mathrm{ka})$ and $164 \% 0(200 \mathrm{ka})$ are associated with ages that are less than $0.5 \%$ younger than the "real" age. Alpha-recoil diffusion from a high [U] coating can cause whole-coral $\delta^{234} U_{\text {initial }}$ elevations with minimal changes to the model age. 
[31] The last two corals (16 ka and $218 \mathrm{ka}$ ) are both septal samples, and are not visibly bioeroded. The processes described in equations (2)-(5) are used to model the diagenesis, but with the presence of a high [U] surface adjacent to the edge of each septa. Both model runs produce spatial patterns and $\delta^{234} U_{\text {initial }}$ ranges that are similar to the observations (Figures $12 \mathrm{~b}$ and 12c). The whole-coral model $\delta^{234} U_{\text {initial }}$ elevations of $149 \%$ and $165 \%$ for the two corals are similar to the observed values of $153 \%$ and $161 \%$. The associated model ages for the $16 \mathrm{ka}$ and $218 \mathrm{ka}$ coral are only $\sim 0.1 \%$ and $1.0 \%$ different from the closed-system ages, respectively.

[32] The differences between real and modeled whole-coral $\delta^{234} U_{\text {initial }}$ values and the discrepancies in the spatial patterns across coral sections may be due to a number of simplifications made in the model. We assume uniform diffusion constants for ${ }^{234} \mathrm{U}^{\mathrm{AR}}$ in each crystal type, but the presence of microcracks and/or micropore waters and variable grain size are likely to cause heterogeneity. Our [U] initial boundary conditions are based on micromilling at a $\sim 100 \mu \mathrm{m}$ scale, but the fission track data show us that $[\mathrm{U}]$ variability is present on a much finer scale. The exact [U] distribution is extremely important in determining the net ${ }^{234} \mathrm{U}$ transfer between subsamples. Small adjustments to the fine-scale $[\mathrm{U}]$ distribution and rate constants would allow us to tune our model results to be identical to the observations.

\subsubsection{Applicability to Shallow-Water Corals}

[33] This study is based on deep-sea scleractinian corals, but shallow-water corals also have primary [U] gradients, are subject to bioerosion and display a similar whole-coral U-Th isotopic distribution (Figure 1). The processes described in this model are therefore likely to be important for shallowwater corals, particularly for those samples that have spent most of their diagenetic history submerged in seawater [Bard et al., 1990b; Toscano and Lundberg, 1999]. Without a detailed knowledge of the U-Th distribution within a specific sample it is not, however, possible to convert closed-system ages to open-system ages

\section{Conclusions}

[34] The presence of [U] heterogeneity within carbonates can lead to the development of large isotopic gradients. The physical processes that cause these gradients are direct transfer of alpharecoil ${ }^{230} \mathrm{Th}$ and ${ }^{234} \mathrm{Th}$ and, more importantly, preferential movement of alpha-decay produced ${ }^{234} \mathrm{U}$ (alpha-recoil diffusion). Internal, closed-system processes cannot alter the apparent age or $\delta^{234} U_{\text {initial }}$ unless coupled with a sampling bias. If the surface has a high [U] coating then alpha-recoil diffusion can lead to large whole-coral $\delta^{234} U_{\text {initial }}$ elevations with little change to the apparent age. By contrast, simultaneous addition of ${ }^{238} \mathrm{U}$ and ${ }^{234} \mathrm{U}$ gives smaller $\delta^{234} \mathrm{U}_{\text {initial }}$ elevations with large age inaccuracies.

\section{Acknowledgment}

[35] We gratefully acknowledge The Comer Foundation for Abrupt Climate Change and the helpful comments of two anonymous reviewers.

\section{References}

Adkins, J. F., H. Cheng, E. A. Boyle, E. R. M. Druffel, and R. L. Edwards (1998), Deep-sea coral evidence for rapid change in ventilation of the deep North Atlantic 15,400 years ago, Science, 280(5364), 725-728.

Adkins, J. F., E. A. Boyle, W. B. Curry, and A. Lutringer (2003), Stable isotopes in deep-sea corals and a new mechanism for "vital effects," Geochim, Cosmochim. Acta, 67(6), 1129-1143.

Adkins, J. F., G. M. Henderson, S. L. Wang, S. O'Shea, and F. Mokadem (2004), Growth rates of the deep-sea scleractinia Desmophyllum cristagalli and Enallopsammia rostrata, Earth Planet. Sci. Lett., 227(3-4), 481-490.

Amiel, A. J., D. S. Miller, and G. M. Friedman (1973), Incorporation of uranium in modern corals, Sedimentology, 20, $523-528$

Bard, E., B. Hamelin, and R. G. Fairbanks (1990a), U-Th ages obtained by mass spectrometry in corals from Barbados: Sea level during the past 130000 years, Nature, 346(6283), 456-458.

Bard, E., B. Hamelin, R. G. Fairbanks, and A. Zindler (1990b), Calibration of the C-14 timescale over the past 30000 years using mass spectrometric U-Th ages from Barbados corals, Nature, 345(6274), 405-409.

Bard, E., R. G. Fairbanks, B. Hamelin, A. Zindler, and H. Chi Trach (1991), Uranium-234 anomalies in corals older than 150000 years, Geochim. Cosmochim. Acta, 55(8), $2385-$ 2390.

Bender, M. L., R. G. Fairbanks, F. W. Taylor, R. K. Matthews, J. G. Goddard, and W. S. Broecker (1979), Uranium-series dating of the Pleistocene reef tracts of Barbados, West Indies, Geol. Soc. Am. Bull., 90(6), I577-I594.

Broecker, W. S. (1963), Preliminary evaluation of uranium series inequilibrium as a tool for absolute age measurement on marine carbonates, J. Geophys. Res., 68(9), 2817-2834.

Broecker, W. S., and T. Takahashi (1966), Calcium carbonate precipitation on the Bahama Banks, J. Geophys. Res., 71(6), $1575-1602$.

Cheng, H., J. Adkins, R. L. Edwards, and E. A. Boyle (2000a), U-Th dating of deep-sea corals, Geochim. Cosmochim. Acta, 64(1-4), 2401-2416. 
Cheng, H., R. L. Edwards, J. Hoff, C. D. Gallup, D. A. Richards, and Y. Asmeron (2000b), The half-lives of uranium-234 and thorium-230, Chem. Geol., 169, 17-33.

Cherniak, D. J. (1997), An experimental study of strontium and lead diffusion in calcite, and implications for the carbonate diagenesis and metamorphism, Geochim. Cosmochim. Acta, 61, 4173-4179.

Cutler, K. B., R. L. Edwards, F. W. Taylor, H. Cheng, J. Adkins, C. D. Gallup, P. M. Cutler, G. S. Burr, and A. L. Bloom (2003), Rapid sea-level fall and deep-ocean temperature change since the last interglacial period, Earth Planet. Sci. Lett., 206(3-4), 253-271.

Djogic, R., G. Kniewald, and M. Branica (1988), Uranium in the marine environment: A geochemical approach to its hydrologic and sedimentary cycle, 1 . Theoretical considerations, in Radionuclides: A Tool for Oceanography, edited by J. C. Guary, P. Guegueniat, and R. J. Pentreath, pp. 171182, Elsevier, New York.

Edwards, R. L., J. H. Chen, and G. J. Wasserburg (1986), ${ }^{238} \mathrm{U}_{-}{ }^{23} \mathrm{U}_{-}{ }^{230} \mathrm{Th}-{ }^{232} \mathrm{Th}$ systematics and the precise measurement of time over the past 500000 years, Earth Planet. Sci. Lett., 81(2-3), 175-192.

Edwards, R. L., H. Cheng, M. T. Murrell, and S. J. Goldstein (1997), Protactinium-231 dating of carbonates by thermal ionization mass spectrometry: Implications for Quaternary climate change, Science, 276(5313), 782-786.

Fleischer, R. L. (1988), Alpha-recoil damage: Relation to isotopic disquilibrium and leaching of radionuclides, Geochim. Cosmochim. Acta, 52(6), 1459-1466.

Frank, N., M. Paterne, L. Ayliffe, T. van Weering, J. P. Henriet, and D. Blamart (2004), Eastern North Atlantic deep-sea corals: Tracing upper intermediate water Delta C-14 during the Holocene, Earth Planet. Sci. Lett., 219(3-4), 297-309.

Gallup, C. D., R. L. Edwards, and R. G. Johnson (1994), The timing of high sea levels over the past 200000 years, Science, 263(5148), 796-800.

Goldstein, S. J., D. W. Lea, S. Chakraborty, M. Kashgarian, and M. T. Murrell (2001), Uranium-series and radiocarbon geochronology of deep-sea corals: Implications for Southern Ocean ventilation rates and the oceanic carbon cycle, Earth Planet. Sci. Lett., 193(1-2), 167-182.

Henderson, G. M. (2002), Seawater $\left({ }^{234} U /{ }^{238} U\right)$, during the last 800 thousand years, Earth Planet. Sci. Lett., 199(1-2), 97-110.

Henderson, G. M., and K. W. Burton (1999), Using $\left({ }^{234} \mathrm{U} /{ }^{238} \mathrm{U}\right)$ to assess diffusion rates of isotope tracers in ferromanganese crusts, Earth Planet. Sci. Lett., 170(3), $169-179$.

Henderson, G. M., N. C. Slowey, and M. Q. Fleisher (2001), U-Th dating of carbonate platform and slope sediments, Geochim. Cosmochim. Acta, 65(18), 2757-2770.

Kigoshi, K. (1971), Alpha-recoil thorium-234: Dissolution into water and the uranium-234/uranium-238 disequilibrium in nature, Science, 173(3991), 47-48.

Lazar, B., R. Enmar, M. Schossberger, M. Bar-Matthews, L. Halicz, and M. Stein (2004), Diagenetic effects on the distribution of uranium in live and Holocene corals from the Gulf of Aqaba, Geochim. Cosmochim. Acta, 68(22), 4583-4593.

Lazier, A. V., J. E. Smith, M. J. Risk, and H. P. Schwarcz (1999), The skeletal structure of Desmophyllum cristagalli: The use of deepwater corals in sclerochronology, Lethaia, $32(2), 119-130$.

Li, Y. H., and S. Gregory (1974), Diffusion of ions in sea water and in deep-sea sediments, Geochim. Cosmochim. Acta, 38, $703-714$.
Lomitschka, M., and A. Mangini (1999), Precise Th/U-dating of small and heavily coated samples of deep sea corals, Earth Planet. Sci. Lett., 170(4), 391-401.

Min, G. R., R. L. Edwards, W. Taylor Frederick, J. Recy, D. Gallup Christina, and J. W. Beck (1995), Annual cycles of $\mathrm{U} / \mathrm{Ca}$ in coral skeletons and $\mathrm{U} / \mathrm{Ca}$ thermometry, Geochim. Cosmochim. Acta, 59(10), 2025-2042.

Montagna, P., M. McCulloch, M. Taviani, A. Remia, and G. Rouse (2005), High-resolution trace and minor element compositions in deep-water scleractinian corals (Desmophyllum dianthus) from the Mediterranean Sea and the Great Australian Bight, in Cold-Water Corals and Ecosystems, edited by A. Freiwald and J. M. Roberts, pp. 1109-1126, Springer, New York.

Murrell, M. T., and D. S. Burnett (1982), Actinide microdistributions in the enstatite meteorites, Geochim. Cosmochim. Acta, 46(12), 2453-2460.

Neff, U., A. Bollhofer, N. Frank, and A. Mangini (1999), Explaining discrepant depth profiles of U-234/U-238 and Th-230 (exc) in Mn-crusts, Geochim. Cosmochim. Acta, 63(15), 2211-2218.

Pingitore, N. E., A. Iglesias, F. Lytle, and G. M. Wellington (2002), X-ray absorption spectroscopy of uranium at low ppm levels in coral skeletal aragonite, Microchem. J., 71(2-3), 261-266.

Reeder, R. J., M. Nugent, C. D. Tait, D. E. Morris, S. M. Heald, K. M. Beck, W. P. Hess, and A. Lanzirotti (2001), Coprecipitation of uranium (VI) with calcite: XAFS, microXAS, and luminescence characterization, Geochim. Cosmochim. Acta, 65(20), 3491-3503.

Robinson, L. F., G. M. Henderson, and N. C. Slowey (2002), U-Th dating of marine isotope stage 7 in Bahamas slope sediments, Earth Planet. Sci. Lett., 196(3-4), 175-187.

Robinson, L. F., G. M. Henderson, L. Hall, and I. Matthews (2004a), Climatic control of riverine and Seawater uraniumisotope ratios, Science, 305(5685), 851-854.

Robinson, L. F., N. S. Belshaw, and G. M. Henderson (2004b), $\mathrm{U}$ and Th concentrations and isotope ratios in modern carbonates and waters from the Bahamas, Geochim. Cosmochim. Acta, 68(8), 1777-1789.

Robinson, L. F., J. F. Adkins, L. D. Keigwin, J. Southon, D. P. Fernandez, S. L. Wang, and D. S. Scheirer (2005), Radiocarbon variability in the western North Atlantic during the last deglaciation, Science, 310, 1469-1473.

Russell, A. D., B. Honisch, H. J. Spero, and D. W. Lea (2004), Effects of seawater carbonate ion concentration and temperature on shell $\mathrm{U}, \mathrm{Mg}$, and $\mathrm{Sr}$ in cultured planktonic foraminifera, Geochim. Cosmochim. Acta, 68(21), 4347-4361.

Scholz, D., A. Mangini, and T. Felis (2004), U-series dating of diagenetically altered fossil reef corals, Earth Planet. Sci. Lett., 218(1-2), 163-178.

Schroder-Ritzrau, A., A. Mangini, and M. Lomitschka (2003), Deep-sea corals evidence periodic reduced ventilation in the North Atlantic during the LGM/Holocene transition, Earth Planet. Sci. Lett., 216(3), 399-410.

Schroeder, J. H., D. S. Miller, and G. M. Friedman (1970), Uranium distribution in recent skeletal carbonates, J. Sediment. Petrol., 40, 672-681.

Shen, G. T., and R. B. Dunbar (1995), Environmental controls on uranium in reef corals, Geochim. Cosmochim. Acta, 59(10), 2009-2024.

Smith, J. E., M. J. Risk, H. P. Schwarcz, and T. A. McConnaughey (1997), Rapid climate change in the North Atlantic during the Younger Dryas recorded by deep-sea corals, Nature, 386(6627), 818-820. 
Smith, J. E., H. P. Schwarcz, M. J. Risk, T. A. McConnaughey, and N. Keller (2000), Paleotemperatures from deep-sea corals: Overcoming 'vital effects', Palaios, 15(1), 25-32.

Stirling, C. H., T. M. Esat, M. T. McCulloch, and K. Lambeck (1995), High-precision U-series dating of corals from Western Australia and implications for the timing and duration of the last interglacial, Earth Planet. Sci. Lett., $135(1-4), 115-130$.

Swart, P. K., and J. A. E. B. Hubbard (1982), Uranium in scleractinian coral skeletons, Coral Reefs, 1, 13-19.

Szabo, B. J., K. R. Ludwig, D. R. Muhs, and K. R. Simmons (1994), Thorium-230 ages of corals and duration of the last interglacial sea-level high stand on Oahu, Hawaii, Science, 266(5182), 93-96.
Thompson, W. G., M. W. Spiegelman, S. L. Goldstein, and R. C. Speed (2003), An open-system model for U-series age determinations of fossil corals, Earth Planet. Sci. Lett., 210, $365-381$.

Toscano, M. A., and J. Lundberg (1999), Submerged late Pleistocene reefs on the tectonically-stable S. E. Florida margin: High-precision geochronology, stratigraphy, resolution of substage 5a sea-level elevation, and orbital forcing, Quat. Sci. Rev., 18(6), 753-767.

Villemant, B., and N. Feuillet (2003), Dating open systems by the U-238-U-234-Th-230 method: Application to Quaternary reef terraces, Earth Planet. Sci. Lett., 210(1-2), 105118. 